\title{
Development of Tectal Connectivity across Metamorphosis in the Bullfrog (Rana catesbeiana)
}

\author{
Seth S. Horowitz Andrea Megela Simmons \\ Department of Cognitive, Linguistic and Psychological Sciences, Department of Neuroscience, Brown University, \\ Providence, R.I., USA
}

\section{Key Words}

Medial septum $\cdot$ Metamorphosis $\cdot$ Midbrain - Multisensory convergence $\cdot$ Nucleus isthmi $\cdot$ Optic tectum $\cdot$ Tadpole $\cdot$ Thalamus

\begin{abstract}
In the bullfrog (Rana catesbeiana), the process of metamorphosis culminates in the appearance of new visual and visuomotor behaviors reflective of the emergence of binocular vision and visually-guided prey capture behaviors as the animal transitions to life on land. Using several different neuroanatomical tracers, we examined the substrates that may underlie these behavioral changes by tracing the afferent and efferent connectivity of the midbrain optic tectum across metamorphic development. Intratectal, tectotoral, tectotegmental, tectobulbar, and tecto-thalamic tracts exhibit similar trajectories of neurobiotin fiber label across the developmental span from early larval tadpoles to adults. Developmental variability was apparent primarily in intensity and distribution of cell and puncta label in target nuclei. Combined injections of cholera toxin subunit $\beta$ and Phaseolus vulgaris leucoagglutinin consistently label cell bodies, puncta, or fiber segments bilaterally in midbrain targets including the pretectal gray, laminar nucleus of the torus semicircularis, and the nucleus of the medial longitudinal fasciculus.
\end{abstract}

Developmentally stable label was observed bilaterally in medullary targets including the medial vestibular nucleus, lateral vestibular nucleus, and reticular gray, and in forebrain targets including the posterior and ventromedial nuclei of the thalamus. The nucleus isthmi, cerebellum, lateral line nuclei, medial septum, ventral striatum, and medial pallium show more developmentally variable patterns of connectivity. Our results suggest that even during larval development, the optic tectum contains substrates for integration of visual with auditory, vestibular, and somatosensory cues, as well as for guidance of motivated behaviors.

Copyright $\odot 2011$ S. Karger AG, Basel

\section{Introduction}

The process of development requires coordination across multiple sensory and motor systems to allow the maturing organism to adapt to changing environmental and physiological demands. Metamorphosis in many anuran amphibians, in which the limbless, herbivorous, aquatic tadpole transforms into a 4-legged, carnivorous, semi-terrestrial frog, is arguably among the more challenging of developmental processes. Along with obvious changes in external body morphology such as the emergence of hind and fore limbs, resorption of the tail, and

\section{KARGER}

(C) 2011 S. Karger AG, Basel

Fax +41613061234 E-Mail karger@karger.ch www.karger.com www.karger.com/bbe
A.M. Simmons

Department of Cognitive, Linguistic and Psychological Sciences

Box 1821, Brown University

Providence, RI 02912 (USA)

Tel. +1 401863 2283, Fax +1 401863 1300,E-Mail Andrea_Simmons@brown.edu 


\begin{tabular}{|c|c|c|c|}
\hline \multicolumn{4}{|c|}{ Abbreviations used in this paper } \\
\hline as & aqueduct of Sylvius & NI & nucleus isthmi \\
\hline $\mathrm{BON}$ & basal optic nucleus & nMLF & nucleus of the medial longitudinal fasciculus \\
\hline $\mathrm{C}$ & central nucleus of the thalamus & oc & optic chiasm \\
\hline $\mathrm{Cb}$ & cerebellum & $\mathrm{OT}$ & optic tectum \\
\hline CerN & cerebellar nucleus & ov & optic ventricle \\
\hline СT $\beta$ & Vibrio cholera toxin $\beta$ subunit & $\mathrm{P}$ & posterior nucleus of the thalamus \\
\hline dap & dorsal arcuate pathway & Para & paragigantocellular nucleus \\
\hline $\mathrm{DMN}$ & dorsal medullary nucleus & $\mathrm{pc}$ & posterior commissure \\
\hline $\mathrm{DP}$ & dorsal pallium & $\mathrm{PD}$ & nucleus posterodorsalis tegmenti mesencephali \\
\hline Ep & entopeduncular nucleus & PHA-L & Phaseolus vulgaris leucoagglutinin \\
\hline HRP & horseradish peroxidase & PTG & pretectal gray \\
\hline III & oculomotor nucleus & RG & reticular gray \\
\hline IV & trochlear nucleus & SON & superior olivary nucleus \\
\hline lfb & lateral forebrain bundle & Str & striatum \\
\hline LLa & anterior lateral line nucleus & tbt & tectobulbar tract \\
\hline LLnp & lateral line neuropil & teg fasc & tegmental fasciculi \\
\hline lot & lateral optic tract & Teg & tegmentum \\
\hline LPD & lateral-posterior nucleus of the thalamus & tlt & tecto-lemniscal pathway \\
\hline LS & lateral septum & TS & torus semicircularis \\
\hline $\operatorname{lv}$ & lateral ventricle & TSl & laminar nucleus of the torus semicircularis \\
\hline LVN & lateral vestibular nucleus & $\mathrm{TSp}$ & principal nucleus of the torus semicircularis \\
\hline $\mathrm{mfb}$ & medial forebrain bundle & vap & ventral arcuate pathway \\
\hline MP & medial pallium & $\mathrm{V}$ & trigeminal nucleus \\
\hline MS & medial septum & VM & ventromedial nucleus of the thalamus \\
\hline MVN & medial vestibular nucleus & & \\
\hline
\end{tabular}

restructuring of the head, metamorphosis also features substantial modifications of sensory systems in preparation for life out of water. Several such modifications have been documented in the auditory system, where a receptor apparatus initially designed for detecting sounds and vibrations underwater must adapt to one capable of operating in air, a medium with different biophysical constraints. In bullfrog (Rana catesbeiana) tadpoles, the progressive formation and maturation of inner ear organs and sound transduction pathways are accompanied by and drive functional and anatomical changes in central auditory nuclei [Boatright-Horowitz and Simmons, 1997; Simmons and Horowitz, 2006; Horowitz et al., 2007a]. During metamorphic climax, the dorsal medulla reorganizes anatomically to encompass sensory input from the newly-emerging external tympanum and to compensate for the degeneration and loss of the lateral line system. Modifications in midbrain-medullary pathways occurring around climax mediate the increased importance of binaural hearing in postmetamorphic life [Horowitz et al., 2007b].

The visual apparatus also undergoes structural modifications over the metamorphic transition. In the bullfrog tadpole, eyes are lidless and without nictitating membranes [Stehouwer, 1988]. These lidless eyes are relatively mobile, likely providing vestibulo-ocular stabilization during swimming. During metamorphic climax stages, a nictitating membrane first appears and ocular mobility gradually decreases. Concurrently, the eyes move from a more lateral to a more dorsal position on the head [Gosner, 1960; Jacobson, 1971]. This results in a broadening of the frontal binocular field appropriate for mediating the postmetamorphic behavioral shift from feeding on stationary plant life to tracking moving animal prey. These considerable changes in visual and visuomotor behaviors likely reflect underlying developmental modification in central visual anatomy and function; unfortunately, experimental analyses of the development of central visual pathways in tadpoles have been limited, both in the number of projections investigated and in the species used for analysis. The time course of maturation of projections from the retina to the optic tectum (OT) has been examined in the leopard frog, R. pipiens, and in the African clawed frog, Xenopus laevis [Jacobson, 1971; Reh and Constantine-Paton, 1984; Sakaguchi and Murphey, 
1985]. The development of connections between the OT and the nucleus isthmi (NI) has also been studied in these 2 species [Grobstein and Comer, 1983; Udin and Fisher, 1985; Chahoud et al., 1996], as well as in Limnodynastes dorsalis [Dann and Beazley, 1982, 1990]. Only a few studies, in larval X. laevis [Chahoud et al., 1996; Deeg et al., 2009] and in larval R. pipiens [Debski and ConstantinePaton, 1993], examined tectal connectivity to medullary and thalamic nuclei. This scarcity of data constrains our understanding of factors that may impact the development and maturation of visual pathways over the dramatic transition of metamorphosis. Because of the differences between larval Xenopus and Rana in optomotor responses [Wassersug, 1971] and the time course and extent of the dorsal migration of the eyes during and after metamorphic climax [Grobstein and Comer, 1977], there are likely differences in the pattern of maturation of visual system anatomy. Moreover, because Xenopus remains fully aquatic after the completion of metamorphosis while Rana becomes semi-terrestrial, the visual systems of these animals are not only subject to different ecological constraints but also respond differently to visual experience [Kennard and Keating, 1985]. Therefore, describing metamorphic changes in visual pathways in anurans on the basis of Xenopus data alone might obscure important species differences in visual anatomy and development related to adult function.

Using several different tract-tracing techniques, we examined the pattern of connectivity from the OT to medullary, midbrain and forebrain target sites over the time course of larval development in the bullfrog. We chose the bullfrog for analysis to complement our previous work [Horowitz et al., 2007b] outlining the considerable variability in the connectivity of brainstem auditory pathways over metamorphic development, and because little is known about visual development in this species. Our results show both stability and modifiability of tectal projection patterns over the metamorphic transition to semiterrestrial life. The overall pattern of connectivity between the OT and many of its target nuclei in the midbrain, medulla, and thalamus is present at early larval stages and remains stable throughout metamorphosis and into postmetamorphic life. This stability highlights the importance of visually-mediated orienting behaviors throughout the life cycle. Alternatively, we also observe a delayed appearance of mature connectivity between the OT and other brainstem and forebrain targets. These more variable patterns might reflect the increased importance of binocular vision and head movements for the stabilization of gaze in terrestrial postmetamorphic animals.

\section{Materials and Methods}

\section{Animals}

All experimental procedures were reviewed and approved by the Brown University Institutional Animal Care and Use Committee, and conform to federal guidelines. R. catesbeiana tadpoles and adults were purchased from a commercial supplier (Dozier Lester, Duson, La., USA). Tadpoles were staged by external morphological criteria based on Gosner [1960] and then classified on the basis of these criteria into 4 stage groups: hatchlings (stages 21-24, the earliest postembryonic stages); early larval (stages 2530 , with undeveloped hindlimb buds), late larval (stages 31-41, with progressive emergence and differentiation of hindlimbs), and metamorphic climax (stages 42-46, with fully-developed hindlimbs, initial emergence progressing to full development of forelimbs, head reshaping, and tail resorption at the end of climax). After completion of metamorphosis, animals were categorized as froglets, subadults, or adults based on snout-vent length [Boatright-Horowitz and Simmons, 1995]. Tadpoles were grouphoused in polycarbonate aquaria containing dechlorinated aerated water ( $\mathrm{pH} \mathrm{7-8)}$ and were fed cooked unsalted spinach and fish flakes ad libitum. Postmetamorphic animals were individually housed in polycarbonate terraria containing both soil and water and were fed live crickets ad libitum. The colony room was maintained at temperatures ranging from $25-28^{\circ} \mathrm{C}$ and on a 12 : 12 light:dark cycle.

\section{Tracer Deposits and Anatomical Staining}

Animals were anesthetized for surgery by immersion in $0.15 \%$ (tadpoles and froglets) or $0.6 \%$ (adults) buffered tricaine methanesulfonate (MS 222, pH 7.0; Sigma, St. Louis, Mo., USA) until all reflexes disappeared. They were wrapped in wet gauze and placed on an ice block for surgery. The OT was exposed by removing overlying cartilaginous tissue (tadpoles) or bone drilling (postmetamorphic animals). Small tears were made in the meninges with a metal microelectrode to accommodate the micropipettes holding tracer.

In 21 animals (tadpoles, $\mathrm{n}=18$; postmetamorphic, $\mathrm{n}=3$ ), we injected into the OT the tracer biotin ethylendiamine (Neurobiotin, SP1120; Vector Laboratories, Burlingame, Calif., USA). Neurobiotin labels cell bodies and fibers in both anterograde and retrograde directions from the injection site [Huang et al., 1992; Jacquin et al., 1992]. For iontophoretic injections ( $\mathrm{n}=7$ animals), a solution of $4 \%$ neurobiotin in $1.0 \mathrm{M}$ potassium chloride was backfilled into $1.0-\mathrm{mm}$ borosilicate glass capillary tubes (1B100F-4; World Precision Instruments, Sarasota, Fla., USA) pulled to a 20 $\mu \mathrm{m}$ tip diameter. Micropipettes were held by a Narishige (Narishige Corp., East Meadow, N.Y., USA) micromanipulator. A silver wire placed into the neurobiotin solution was connected to a constant current source (Model 51413; Stoelting, Wood Dale, Ill., USA). Micropipettes were placed at approximately the rostralcaudal point (mid-levels) of 1 tectal lobe, targeting both more medial and more lateral locations; the size of the surgical opening typically prevented visually-guided placement of the pipette at either very caudal or very rostral tectal locations. Iontophoresis was carried out using $0.4-0.6 \mu \mathrm{A}$ alternating current for $3 \mathrm{~min}$. The micropipette remained in place for $5 \mathrm{~min}$ after termination of the current in order to allow the tracer to permeate the brain region. The site was then thoroughly rinsed with $0.9 \%$ sterile saline, and antiseptic Gelfoam (Upjohn, Kalamazoo, Mich., USA) 
was placed in the wound. Pressure injections (106-212 nl; $\mathrm{n}=14$ animals) were performed using a $10-\mu l$ manual microinjector (Sutter Instruments, Novato, Calif., USA) or a Nanoject II (Drummond Scientific, Broomall, Pa., USA). Tracer was again targeted to the mid-levels of 1 tectal lobe, with approximately equal numbers of medial and lateral injections attempted. The skin was closed using 5/0 Vicryl (Ethicon, Somerville, N.J., USA) sutures, and triple antibiotic containing lidocaine (Neosporin; Pfizer, Cambridge, Mass., USA) was topically applied. Animals were housed singly in polycarbonate aquaria with aerated water until euthanasia. Recovery times ranged from 4 to $24 \mathrm{~h}$ for tadpoles and from 4 to $48 \mathrm{~h}$ for postmetamorphic animals. Careful analysis of the data revealed no significant differences in distance of tracer travel or location of target area based on either recovery time or mode of injection. In additional experiments ( $\mathrm{n}=3$ tadpoles, $\mathrm{n}=$ 1 froglet), we performed much larger injections and allowed the animals to survive $24 \mathrm{~h}$. These larger injections produced considerable tracer leakage into the lateral regions of the torus semicircularis (TS) and tegmentum (Teg), thus complicating the separation of tectal projections from those of these other brain nuclei. For this reason, data in this paper are based on smaller OT injections that did not include leakage into the TS or Teg.

In 31 animals (tadpoles, $\mathrm{n}=26$; postmetamorphic, $\mathrm{n}=5$ ), we co-injected the tracers Phaseolus vulgaris leucoagglutinin (PHAL; L32455; Invitrogen, Eugene, Oreg., USA) and Vibrio cholera toxin $\beta$ subunit (CT $\beta$; 222841 ; Invitrogen) at approximately the rostral-caudal midpoint of 1 tectal lobe, targeting similar numbers of medial and lateral locations. These tracers were conjugated to AlexaFluor 568 and 488, providing fluorescent label of orange/red and green, respectively. PHA-L is a strong anterograde tracer, while CT $\beta$ is a robust retrograde tracer that undergoes weaker anterograde transport; neither tracer shows transneuronal transport [Gerfen and Sawchenko, 1984; Luppi et al., 1995]. The simultaneous use of these 2 tracers allowed us to investigate the distribution of afferent and efferent processes from the same injection site. Our data show evidence of some limited anterograde transport of CT $\beta$, but no retrograde transport of PHA-L. A glass micropipette (20-40 $\mu \mathrm{m}$ tip diameter) was backfilled with tracer, and manipulated into the OT (approximately midway between very rostral and very caudal locations) under visual control. Tracer (106-212 nl) was pressure-injected as described above. The micropipette remained in place for $5 \mathrm{~min}$ after injection, and the wound was closed as described above. Animals were allowed to recover for $1(n=15), 2(n=2)$ or $3(n=11)$ days before euthanasia. Although longer survival times produced greater intensity of label, there were no consistent differences in identity of target areas related to survival time.

Several control experiments were performed to assess any patterns of label due to tracer leakage and to help interpret possible fiber of passage label. In 18 animals (tadpoles: $n=16$; postmetamorphic: $\mathrm{n}=2$ ), tracers (PHA-L/CT $\beta, \mathrm{n}=12$; neurobiotin, $\mathrm{n}=6$ ) were deliberately injected into the choroid plexus overlying the medulla, the membranes overlying the OT, or directly into the optic ventricle, at the same approximate volumes as used for OT injections. In none of these animals did we observe anything other than limited periventricular label or label of the membranes surrounding the brain, with no consistent label of brain parenchyma. In 13 other tadpoles, small injections (PHA-L/CT $\beta, \mathrm{n}=$ 10 ; neurobiotin, $\mathrm{n}=3$ ) were made directly into the TS. Data from these injections were compared to those described elsewhere
[Horowitz et al., 2007b] and used to assess fiber of passage label and any leakage from large OT injections.

At the end of the recovery period, animals were immersed in $0.6 \%$ MS 222 until all reflexes disappeared. They were transcardially perfused with heparinized $0.9 \%$ saline followed by $4 \%$ paraformaldehyde ( $\mathrm{pH}$ 7.4). Brains were removed and postfixed overnight at $4^{\circ} \mathrm{C}$ in $4 \%$ paraformaldehyde. Overlying meninges were removed and brains were embedded in agarose (5\% in saline; ISC BioExpress, Kaysville, Utah, USA) and sliced by vibratomy (50 $\mu \mathrm{m}$ coronal or $75 \mu \mathrm{m}$ horizontal sections; Vibratome, St Louis, Mo., USA). In a subset of animals, the retina contralateral to the injection site in the OT was removed and flat-mounted to provide an indication of tracer spread. Sections from neurobiotin injected brains were mounted on gelatin-subbed slides, rinsed 3 times for 20 min in $1 \times$ phosphate buffered saline (PBS, pH 7.4) with $1 \%$ Triton-X 100 (Sigma) for $24 \mathrm{~h}$ at $4{ }^{\circ} \mathrm{C}$, then incubated in streptavidin Alexa Fluor 488 conjugate (1:200 dilution; Invitrogen) for $24 \mathrm{~h}$ at $4^{\circ} \mathrm{C}$, producing a green fluorescence. Following incubation, sections were rinsed overnight in $1 \times$ PBS, and cover slipped with non-fluorescent mounting medium (Aqua Poly/Mount; Polysciences, Warrington, Pa., USA). In brains with PHA-L/CT $\beta$ injections, sections were directly mounted on gelatin-subbed slides. Some sections were counterstained with $0.5 \%$ cresyl violet acetate ( $\mathrm{pH} 3.7$ using glacial acetic acid) to ease identification of nuclear boundaries, and were mounted with Cytoseal (Fisher Scientific, Pittsburgh, Pa., USA).

\section{Image Processing and Analyses}

Brain sections were visualized and imaged using an Olympus BX60 research microscope (Melville, N.Y., USA) equipped with custom-made fluorescence cubes and an Olympus DP72 camera (Olympus America, Center Valley, Pa., USA). Images were acquired using a Dell Pentium IV 2.4GHz computer running image acquisition and analysis software (Olympus) and were stored as 24-bit RGB TIFF images. Images were contrast adjusted and color balanced to match luminance between sections. Schematization of cell bodies and nerve terminal location was carried out by dividing 24-bit RGB TIFF files into red (PHA-L), green (CT 3 ) and blue (cresyl violet) 8 -bit grayscale images, converting these to thresholded binary images, tracing the edges of the objects and passing the tracings through particle size filters with parameters based on a selection of 25 randomly chosen cells from the regions of interest (Image J, National Institutes of Health, Bethesda, Md., USA). Selected sections were mounted in AntiFade (Invitrogen) and imaged using a Leica TCS SP2 confocal microscope system (sequential scan mode; Leica Microsystems, Bannockburn, Ill., USA). High power $\mathrm{z}$ stack images were taken through each section and viewed in orthogonal planes using Leica confocal software (Leica Microsystems).

To provide an indication of the relative intensity of label present in particular target areas, the authors and a research assistant blind to the hypothesis of the experiment independently categorized label in that target area as none to minimal, sparse/light, moderate, or heavy (tables 1-3). These categorizations were combined across the raters and across stages separately for each of the 4 different larval stage groups, early postmetamorphic (froglets and subadults) frogs, and adult frogs. At all developmental stage groups, similar amounts of tracers were injected, and so the aggregate data from any particular group reflect comparable numbers of relatively larger and relatively smaller injection sites with- 
in the limited range we used. Tables show the most common rating of label within a particular target area across all animals within that developmental group; individual animals within a group could show some variability from these typical patterns, attributable to the size of a particular injection site.

\section{Results}

\section{Injection Sites and Nomenclature}

The OT of bullfrog tadpoles does not clearly show 6 distinct layers until around stages 26-28, during the early larval period [Horowitz and Simmons, 2007]. Throughout the rest of larval development, deep layers are more densely packed than superficial layers and comprise a relatively larger proportion of overall tectal depth than seen in postmetamorphic frogs. From the end of the late larval period through the froglet period, superficial layers increase in thickness by about $50 \%$. These changes in lamination make quantitative comparisons of laminar position of injections at different developmental stages difficult, and do not allow precise limitation of injections to any 1 layer. Most injection sites (neurobiotin, $\mathrm{n}=17$; $\mathrm{PHA}-$ $\mathrm{L} / \mathrm{CT} \beta, \mathrm{n}=27$ ) were centered in mid or deep tectal layers (fig. 1). Because of the small number of superficial injections, we could not determine any relationship between depth of injection and intensity of label in target nuclei.

The majority (neurobiotin, $\mathrm{n}=19$; PHA-L/CT $\beta, \mathrm{n}=$ 22) of injection sites were located at mid-levels of the OT, as targeted, across its entire medial-lateral dimension (fig. 1). In 2 tadpoles (fig. 1A), injection sites were centered deep and laterally near the lateral border of the laminar nucleus of the torus semicircularis (TS1). Projections emanating from these injections were overall similar to those from more shallower and more medial injections, but produced qualitatively greater intensity of label in acoustic nuclei - the dorsal medullary nucleus (DMN), superior olivary nucleus (SON), and in the posterior and central nuclei of the thalamus. Additional injection sites (neurobiotin, $\mathrm{n}=2$; PHA-L/CT $\beta, \mathrm{n}=6$ ) were located at rostral levels of the OT, near or in the boundaries of the pretectum as defined in adult ranids. Diameters of injection sites (measured at the widest point) ranged from 35$250 \mu \mathrm{m}$. There was no correlation between developmental stage and size of injection. Qualitatively more intense label was more often observed after larger compared to smaller tracer deposits at any given survival time; however, the relative amount of tracer injected, within the small range we used, did not alter the overall pattern of connectivity (identity of target areas) in any particular developmental group. Unless otherwise noted, figures
Table 1. Qualitative intensity of anterograde and retrograde labeled fibers in target regions after neurobiotin injections into the $\mathrm{OT}$

\begin{tabular}{|c|c|c|c|c|c|}
\hline \multirow[t]{2}{*}{ Site } & \multicolumn{5}{|c|}{ Developmental stage group/n } \\
\hline & $\begin{array}{l}\text { early } \\
25-30 \\
(n=5)\end{array}$ & $\begin{array}{l}\text { late } \\
31-41 \\
(n=7)\end{array}$ & $\begin{array}{l}\text { climax } \\
42-46 \\
(n=4)\end{array}$ & $\begin{array}{l}\text { froglet } \\
(\mathrm{n}=2)\end{array}$ & $\begin{array}{l}\text { adult } \\
(\mathrm{n}=1)\end{array}$ \\
\hline \multicolumn{6}{|l|}{ Medulla } \\
\hline dap & $2 \mathrm{I} ; 2 \mathrm{C}$ & $2 \mathrm{I} ; 2 \mathrm{C}$ & $2 \mathrm{I} ; 2 \mathrm{C}$ & $3 \mathrm{I} ; 3 \mathrm{C}$ & 3I; 3C \\
\hline LLnp & $1 \mathrm{I} ; 1 \mathrm{C}$ & $1 \mathrm{I} ; 1 \mathrm{C}$ & 0I; 0C & - & - \\
\hline MVN & $1 \mathrm{I} ; 1 \mathrm{C}$ & $2 \mathrm{I} ; 2 \mathrm{C}$ & $2 \mathrm{I} ; 2 \mathrm{C}$ & $2 \mathrm{I} ; 2 \mathrm{C}$ & $2 \mathrm{I} ; 2 \mathrm{C}$ \\
\hline RG & $2 \mathrm{I} ; 2 \mathrm{C}$ & $2 \mathrm{I} ; 2 \mathrm{C}$ & $3 \mathrm{I} ; 3 \mathrm{C}$ & $3 \mathrm{I} ; 3 \mathrm{C}$ & 3I; 3C \\
\hline vap & $1 \mathrm{I} ; 0 \mathrm{C}$ & 1I; 0C & $1 \mathrm{I} ; 1 \mathrm{C}$ & $2 \mathrm{I} ; 1 \mathrm{C}$ & 2I; $1 \mathrm{C}$ \\
\hline \multicolumn{6}{|l|}{ Midbrain } \\
\hline NI & $1 \mathrm{I} ; 1 \mathrm{C}$ & $2 \mathrm{I} ; 1 \mathrm{C}$ & $2 \mathrm{I} ; 1 \mathrm{C}$ & $3 \mathrm{I} ; 2 \mathrm{C}$ & $3 \mathrm{I} ; 2 \mathrm{C}$ \\
\hline OT & $2 \mathrm{I} ; 1 \mathrm{C}$ & $2 \mathrm{I} ; 2 \mathrm{C}$ & $3 \mathrm{I} ; 2 \mathrm{C}$ & $3 \mathrm{I} ; 3 \mathrm{C}$ & $3 \mathrm{I} ; 3 \mathrm{C}$ \\
\hline PD & $2 \mathrm{I} ; 2 \mathrm{C}$ & $2 \mathrm{I} ; 2 \mathrm{C}$ & $2 \mathrm{I} ; 2 \mathrm{C}$ & $2 \mathrm{I} ; 2 \mathrm{C}$ & $2 \mathrm{I} ; 2 \mathrm{C}$ \\
\hline tbt & $2 \mathrm{I} ; 1 \mathrm{C}$ & $2 \mathrm{I} ; 1 \mathrm{C}$ & $3 \mathrm{I} ; 2 \mathrm{C}$ & $3 \mathrm{I} ; 2 \mathrm{C}$ & $3 \mathrm{I} ; 2 \mathrm{C}$ \\
\hline teg fasc & $2 \mathrm{I} ; 2 \mathrm{C}$ & $2 \mathrm{I} ; 2 \mathrm{C}$ & $3 \mathrm{I} ; 3 \mathrm{C}$ & 3I; 3C & 3I; 3C \\
\hline tlt & $2 \mathrm{I} ; 2 \mathrm{C}$ & $2 \mathrm{I} ; 2 \mathrm{C}$ & $3 \mathrm{I} ; 3 \mathrm{C}$ & 3I; 3C & 3I; 3C \\
\hline TSl & $1 \mathrm{I} ; 1 \mathrm{C}$ & $1 \mathrm{I} ; 1 \mathrm{C}$ & $1 \mathrm{I} ; 1 \mathrm{C}$ & $1 \mathrm{I} ; 1 \mathrm{C}$ & 1I; 1C \\
\hline TSp & $1 \mathrm{I} ; 0 \mathrm{C}$ & 1I; 1C & $2 \mathrm{I} ; 1 \mathrm{C}$ & $2 \mathrm{I} ; 1 \mathrm{C}$ & $2 \mathrm{I} ; 2 \mathrm{C}$ \\
\hline \multicolumn{6}{|l|}{ Thalamus } \\
\hline lfb & $1 \mathrm{I} ; 1 \mathrm{C}$ & $1 \mathrm{I} ; 1 \mathrm{C}$ & $1 \mathrm{I} ; 1 \mathrm{C}$ & $1 \mathrm{I} ; 1 \mathrm{C}$ & 1I; $1 \mathrm{C}$ \\
\hline lot & $2 \mathrm{I} ; 2 \mathrm{C}$ & 3I; 3C & $3 \mathrm{I} ; 3 \mathrm{C}$ & $3 \mathrm{I} ; 3 \mathrm{C}$ & 3I; 3C \\
\hline $\mathrm{mfb}$ & $1 \mathrm{I} ; 1 \mathrm{C}$ & $2 \mathrm{I} ; 2 \mathrm{C}$ & $2 \mathrm{I} ; 2 \mathrm{C}$ & $2 \mathrm{I} ; 2 \mathrm{C}$ & 2I; 2C \\
\hline oc & $2 \mathrm{I} ; 2 \mathrm{C}$ & 3I; 3C & $3 \mathrm{I} ; 3 \mathrm{C}$ & $3 \mathrm{I} ; 3 \mathrm{C}$ & 3I; 3C \\
\hline $\mathrm{pc}$ & $2 \mathrm{I} ; 2 \mathrm{C}$ & $2 \mathrm{I} ; 2 \mathrm{C}$ & $2 \mathrm{I} ; 2 \mathrm{C}$ & $2 \mathrm{I} ; 2 \mathrm{C}$ & $2 \mathrm{I} ; 2 \mathrm{C}$ \\
\hline PTG & $2 \mathrm{I} ; 2 \mathrm{C}$ & $2 \mathrm{I} ; 2 \mathrm{C}$ & $2 \mathrm{I} ; 2 \mathrm{C}$ & $2 \mathrm{I} ; 2 \mathrm{C}$ & 3I; 3C \\
\hline \multicolumn{6}{|c|}{ Telencephalon } \\
\hline MS & $1 \mathrm{I} ; 1 \mathrm{C}$ & $2 \mathrm{I} ; 2 \mathrm{C}$ & $2 \mathrm{I} ; 2 \mathrm{C}$ & $2 \mathrm{I} ; 2 \mathrm{C}$ & $2 \mathrm{I} ; 2 \mathrm{C}$ \\
\hline
\end{tabular}

Entries are the most common rating for all brains within that stage group. Animals are staged and classified as described previously [Gosner, 1960; Boatright-Horowitz and Simmons, 1997]. Data for hatchlings $(n=2)$ are not included in this table. The dashes for the LLnp in froglets and adults indicate that this area is no longer present at these developmental times. I = Ipsilateral; $\mathrm{C}=$ contralateral $; 0=$ none to $\operatorname{minimal} ; 1=$ sparse $/$ light $; 2=\bmod -$ erate; 3 = heavy.

show results of injections centered at mid, rather than rostral, levels of the OT.

Anatomical boundaries in tadpole brains differ from those in postmetamorphic brains, due to growth in overall size, changes in shape, and internal reorganization [Horowitz et al., 2007b]. We describe anatomical boundaries in tadpole brains based on our own in-house atlases (fig. 2A). Nomenclature is consistent with that used in adult ranid brains [Nieuwenhuys and Opdam, 1976; Wilczynski and Northcutt, 1977; Wada et al., 1980]. 
Table 2. Qualitative intensity of retrograde cell body label in target nuclei after CT $\beta$ injections into the OT

\begin{tabular}{|c|c|c|c|c|c|}
\hline \multirow[t]{2}{*}{ Site } & \multicolumn{5}{|c|}{ Developmental stage group/n } \\
\hline & $\begin{array}{l}\text { early } \\
25-30 \\
(n=5)\end{array}$ & $\begin{array}{l}\text { late } \\
31-41 \\
(\mathrm{n}=12)\end{array}$ & $\begin{array}{l}\text { climax } \\
42-46 \\
(n=9)\end{array}$ & $\begin{array}{l}\text { froglet } \\
\text { subadult } \\
(n=3)\end{array}$ & $\begin{array}{l}\text { adult } \\
(\mathrm{n}=2)\end{array}$ \\
\hline \multicolumn{6}{|l|}{ Hindbrain } \\
\hline $\mathrm{Cb}$ & 1I; 0C & $2 \mathrm{I} ; 1 \mathrm{C}$ & $2 \mathrm{I} ; 2 \mathrm{C}$ & $2 \mathrm{I} ; 2 \mathrm{C}$ & $2 \mathrm{I} ; 2 \mathrm{C}$ \\
\hline CerN & 1I; 0C & $2 \mathrm{I} ; 1 \mathrm{C}$ & $2 \mathrm{I} ; 1 \mathrm{C}$ & $1 \mathrm{I} ; 1 \mathrm{C}$ & $1 \mathrm{I} ; 1 \mathrm{C}$ \\
\hline $\mathrm{DMN}$ & 0I; 0C & 0I; 0C & $1 \mathrm{I} ; 0 \mathrm{C}$ & $1 \mathrm{I} ; 0 \mathrm{C}$ & 1I; 0C \\
\hline LLa & 2I; 0C & $2 \mathrm{I} ; 1 \mathrm{C}$ & 0I; 0C & - & - \\
\hline LVN & $2 \mathrm{I} ; 2 \mathrm{C}$ & $3 \mathrm{I} ; 3 \mathrm{C}$ & $3 \mathrm{I} ; 3 \mathrm{C}$ & $3 \mathrm{I} ; 3 \mathrm{C}$ & 3I; 3C \\
\hline MVN & 1I; 1C & $2 \mathrm{I} ; 1 \mathrm{C}$ & $2 \mathrm{I} ; 2 \mathrm{C}$ & $3 \mathrm{I} ; 3 \mathrm{C}$ & $2 \mathrm{I} ; 2 \mathrm{C}$ \\
\hline Para & $2 \mathrm{I} ; 2 \mathrm{C}$ & $2 \mathrm{I} ; 2 \mathrm{C}$ & $2 \mathrm{I} ; 2 \mathrm{C}$ & $2 \mathrm{I} ; 2 \mathrm{C}$ & $2 \mathrm{I} ; 2 \mathrm{C}$ \\
\hline RG & 2I; 2C & $2 \mathrm{I} ; 2 \mathrm{C}$ & 2I; 2C & $3 \mathrm{I} ; 3 \mathrm{C}$ & 3I; 3C \\
\hline SON & $1 \mathrm{I} ; 0 \mathrm{C}$ & $1 \mathrm{I} ; 0 \mathrm{C}$ & 1I; 0C & $1 \mathrm{I} ; 0 \mathrm{C}$ & $2 \mathrm{I} ; 0 \mathrm{C}$ \\
\hline $\mathrm{V}$ & OI; 0C & $1 \mathrm{I} ; 1 \mathrm{C}$ & $1 \mathrm{I} ; 1 \mathrm{C}$ & $1 \mathrm{I} ; 1 \mathrm{C}$ & 1I; 1C \\
\hline \multicolumn{6}{|l|}{ Midbrain } \\
\hline NI & $1 \mathrm{I} ; 1 \mathrm{C}$ & $2 \mathrm{I} ; 1 \mathrm{C}$ & $2 \mathrm{I} ; 1 \mathrm{C}$ & $3 \mathrm{I} ; 2 \mathrm{C}$ & $3 \mathrm{I} ; 2 \mathrm{C}$ \\
\hline nMLF & $2 \mathrm{I} ; 1 \mathrm{C}$ & $2 \mathrm{I} ; 1 \mathrm{C}$ & $3 \mathrm{I} ; 2 \mathrm{C}$ & $3 \mathrm{I} ; 2 \mathrm{C}$ & $3 \mathrm{I} ; 2 \mathrm{C}$ \\
\hline OT & $2 \mathrm{I} ; 2 \mathrm{C}$ & $3 \mathrm{I} ; 2 \mathrm{C}$ & $3 \mathrm{I} ; 2 \mathrm{C}$ & $3 \mathrm{I} ; 1 \mathrm{C}$ & $3 \mathrm{I} ; 1 \mathrm{C}$ \\
\hline $\mathrm{PD}$ & 2I; 1C & $3 \mathrm{I} ; 2 \mathrm{C}$ & 3I; 3C & $3 \mathrm{I} ; 3 \mathrm{C}$ & $2 \mathrm{I} ; 2 \mathrm{C}$ \\
\hline Teg & 1I; 0C & $2 \mathrm{I} ; 1 \mathrm{C}$ & 2I; $1 \mathrm{C}$ & $2 \mathrm{I} ; 1 \mathrm{C}$ & $2 \mathrm{I} ; 1 \mathrm{C}$ \\
\hline TSl & 1I; 1C & $2 \mathrm{I} ; 1 \mathrm{C}$ & $2 \mathrm{I} ; 1 \mathrm{C}$ & $2 \mathrm{I} ; 1 \mathrm{C}$ & 2I; 1C \\
\hline $\mathrm{TSp}$ & 1I; 0C & $1 \mathrm{I} ; 1 \mathrm{C}$ & $1 \mathrm{I} ; 1 \mathrm{C}$ & $2 \mathrm{I} ; 1 \mathrm{C}$ & $2 \mathrm{I} ; 1 \mathrm{C}$ \\
\hline IV & 0I; 0C & 1I; $1 \mathrm{C}$ & $1 \mathrm{I} ; 1 \mathrm{C}$ & $2 \mathrm{I} ; 2 \mathrm{C}$ & $2 \mathrm{I} ; 2 \mathrm{C}$ \\
\hline \multicolumn{6}{|l|}{ Thalamus } \\
\hline Anterior & OI; 0C & 0I; 0C & 1I; 0C & $2 \mathrm{I} ; 0 \mathrm{C}$ & 2I; 0C \\
\hline III & OI; 0C & 0I; 0C & $1 \mathrm{I} ; 1 \mathrm{C}$ & $2 \mathrm{I} ; 2 \mathrm{C}$ & $2 \mathrm{I} ; 2 \mathrm{C}$ \\
\hline LPD & $1 \mathrm{I} ; 1 \mathrm{C}$ & $2 \mathrm{I} ; 2 \mathrm{C}$ & $2 \mathrm{I} ; 2 \mathrm{C}$ & $2 \mathrm{I} ; 2 \mathrm{C}$ & $2 \mathrm{I} ; 2 \mathrm{C}$ \\
\hline Posterior & $1 \mathrm{I} ; 1 \mathrm{C}$ & $2 \mathrm{I} ; 2 \mathrm{C}$ & $2 \mathrm{I} ; 2 \mathrm{C}$ & $2 \mathrm{I} ; 2 \mathrm{C}$ & $2 \mathrm{I} ; 2 \mathrm{C}$ \\
\hline VM & $1 \mathrm{I} ; 1 \mathrm{C}$ & $2 \mathrm{I} ; 2 \mathrm{C}$ & $2 \mathrm{I} ; 2 \mathrm{C}$ & $2 \mathrm{I} ; 2 \mathrm{C}$ & $2 \mathrm{I} ; 1 \mathrm{C}$ \\
\hline \multicolumn{6}{|l|}{ Telencephalon } \\
\hline LS & $1 \mathrm{I} ; 1 \mathrm{C}$ & 1I; 1C & $1 \mathrm{I} ; 1 \mathrm{C}$ & $2 \mathrm{I} ; 2 \mathrm{C}$ & $1 \mathrm{I} ; 1 \mathrm{C}$ \\
\hline MS & $1 \mathrm{I} ; 1 \mathrm{C}$ & $2 \mathrm{I} ; 2 \mathrm{C}$ & $2 \mathrm{I} ; 2 \mathrm{C}$ & $2 \mathrm{I} ; 2 \mathrm{C}$ & $1 \mathrm{I} ; 1 \mathrm{C}$ \\
\hline MP & OI; 0C & 1I; 1C & 1I; $1 \mathrm{C}$ & $1 \mathrm{I} ; 1 \mathrm{C}$ & $1 \mathrm{I} ; 1 \mathrm{C}$ \\
\hline Str & OI; 0C & OI; OC & $1 \mathrm{I} ; 1 \mathrm{C}$ & $1 \mathrm{I} ; 1 \mathrm{C}$ & $1 \mathrm{I} ; 1 \mathrm{C}$ \\
\hline
\end{tabular}

Entries are the most common rating for all brains within that stage group. Data from individual animals within that stage group may vary somewhat from this common rating, due primarily to size of the injection site. The dashes for the LLa in froglets and adults indicate that this nucleus is no longer present at these developmental times. $\mathrm{I}=$ Ipsilateral; $\mathrm{C}=$ contralateral; $0=$ none to minimal; 1 = sparse $/$ light $2=$ moderate; $3=$ heavy.

\section{Trajectory of Neurobiotin Fiber Label}

The major developmental trends in the pattern of neurobiotin fiber label are increases in the relative intensity of label over development and the loss of label in the lateral line neuropil (LLnp) beginning in metamorphic climax
Table 3. Qualitative intensity of anterograde puncta label in target nuclei after PHA-L injections into the OT

\begin{tabular}{|c|c|c|c|c|c|}
\hline \multirow[t]{2}{*}{ Site } & \multicolumn{5}{|c|}{ Developmental stage group/n } \\
\hline & $\begin{array}{l}\text { early } \\
25-30 \\
(n=5)\end{array}$ & $\begin{array}{l}\text { late } \\
31-41 \\
(n=12)\end{array}$ & $\begin{array}{l}\text { climax } \\
42-46 \\
(n=9)\end{array}$ & $\begin{array}{l}\text { froglet } \\
\text { subadult } \\
(\mathrm{n}=3)\end{array}$ & $\begin{array}{l}\text { adult } \\
(\mathrm{n}=2)\end{array}$ \\
\hline \multicolumn{6}{|l|}{ Hindbrain } \\
\hline $\mathrm{Cb}$ & 0I; 0C & $1 \mathrm{I} ; 1 \mathrm{C}$ & 2I; 1C & $1 \mathrm{I} ; 1 \mathrm{C}$ & $1 \mathrm{I} ; 1 \mathrm{C}$ \\
\hline CerN & 0I; 0C & 0I; 0C & 1I; 1C & $1 \mathrm{I} ; 1 \mathrm{C}$ & $1 \mathrm{I} ; 1 \mathrm{C}$ \\
\hline LLnp & $1 \mathrm{I} ; 1 \mathrm{C}$ & $1 \mathrm{I} ; 1 \mathrm{C}$ & 1I; 0C & - & - \\
\hline MVN & $2 \mathrm{I} ; 2 \mathrm{C}$ & $2 \mathrm{I} ; 2 \mathrm{C}$ & 2I; 2C & $2 \mathrm{I} ; 2 \mathrm{C}$ & $2 \mathrm{I} ; 2 \mathrm{C}$ \\
\hline RG & $2 \mathrm{I} ; 2 \mathrm{C}$ & $2 \mathrm{I} ; 2 \mathrm{C}$ & 2I; 2C & $2 \mathrm{I} ; 2 \mathrm{C}$ & $1 \mathrm{I} ; 1 \mathrm{C}$ \\
\hline \multicolumn{6}{|l|}{ Midbrain } \\
\hline $\mathrm{NI}$ & $1 \mathrm{I} ; 0 \mathrm{C}$ & $1 \mathrm{I} ; 0 \mathrm{C}$ & 2I; 0C & $2 \mathrm{I} ; 0 \mathrm{C}$ & $2 \mathrm{I} ; 0 \mathrm{C}$ \\
\hline nMLF & $2 \mathrm{I} ; 1 \mathrm{C}$ & 2I; 1C & 2I; 1C & $2 \mathrm{I} ; 1 \mathrm{C}$ & $2 \mathrm{I} ; 1 \mathrm{C}$ \\
\hline $\mathrm{PD}$ & $1 \mathrm{I} ; 1 \mathrm{C}$ & $1 \mathrm{I} ; 1 \mathrm{C}$ & 1I; 0C & $1 \mathrm{I} ; 1 \mathrm{C}$ & $1 \mathrm{I} ; 1 \mathrm{C}$ \\
\hline OT & $3 \mathrm{I} ; 1 \mathrm{C}$ & $3 \mathrm{I} ; 1 \mathrm{C}$ & 3I; $1 \mathrm{C}$ & $3 \mathrm{I} ; 1 \mathrm{C}$ & $3 \mathrm{I} ; 1 \mathrm{C}$ \\
\hline Teg & $2 \mathrm{I} ; 0 \mathrm{C}$ & $2 \mathrm{I} ; 1 \mathrm{C}$ & 2I; 1C & $2 \mathrm{I} ; 1 \mathrm{C}$ & $2 \mathrm{I} ; 1 \mathrm{C}$ \\
\hline TSl & $1 \mathrm{I} ; 1 \mathrm{C}$ & $2 \mathrm{I} ; 1 \mathrm{C}$ & 2I; 1C & 2I; 1C & $2 \mathrm{I} ; 1 \mathrm{C}$ \\
\hline TSp & 0I; 0C & 1I; 0C & 1I; 1C & $1 \mathrm{I} ; 1 \mathrm{C}$ & $1 \mathrm{I} ; 1 \mathrm{C}$ \\
\hline \multicolumn{6}{|l|}{ Thalamus } \\
\hline Anterior & 0I; 0C & 1I; 0C & 2I; 1C & $2 \mathrm{I} ; 1 \mathrm{C}$ & $2 \mathrm{I} ; 1 \mathrm{C}$ \\
\hline LPD & $1 \mathrm{I} ; 1 \mathrm{C}$ & $1 \mathrm{I} ; 1 \mathrm{C}$ & 2I; 1C & $1 \mathrm{I} ; 1 \mathrm{C}$ & $1 \mathrm{I} ; 1 \mathrm{C}$ \\
\hline VM & $1 \mathrm{I} ; 1 \mathrm{C}$ & $1 \mathrm{I} ; 1 \mathrm{C}$ & 2I; 2C & $1 \mathrm{I} ; 1 \mathrm{C}$ & $1 \mathrm{I} ; 1 \mathrm{C}$ \\
\hline Ep & $2 \mathrm{I} ; 2 \mathrm{C}$ & $2 \mathrm{I} ; 2 \mathrm{C}$ & 2I; 2C & $2 \mathrm{I} ; 2 \mathrm{C}$ & $1 \mathrm{I} ; 1 \mathrm{C}$ \\
\hline \multicolumn{6}{|c|}{ Telencephalon } \\
\hline $\mathrm{MP}$ & 0I; 0C & $1 \mathrm{I} ; 0 \mathrm{C}$ & 1I; 0C & 1I; 0C & 1I; 0C \\
\hline
\end{tabular}

Entries are the most common rating for all brains within that stage group. Data from individual animals within that stage group may vary somewhat from this common rating, due primarily to size of the injection site. The dashes for the LLnp in froglets and adults indicate that this area is no longer present at these developmental times. $\mathrm{I}=$ Ipsilateral; $\mathrm{C}=$ contralateral; $0=$ none to minimal; 1 = low/light; 2 = moderate; 3 = heavy.

(table 1). In hatchling tadpoles $(\mathrm{n}=2)$, injections into the medial OT resulted in fiber and cell body label around the injection site, extending towards the ipsilateral dorsal Teg (fig. 3A) and pretectal gray (PTG). Caudally, labeled fibers coursed laterally in the midbrain towards the medulla. Rostrally, moderate label of the tecto-thalamic tract was seen up to the level of the optic chiasm (oc), but there was no label in the telencephalon, even after large injections.

In early larval through metamorphic climax tadpoles, injections of neurobiotin into either mid (fig. 2B) or rostral levels of the OT yielded moderate to heavy cell body and fiber label in the ipsilateral OT. Deep injections labeled more fibers in mid and deep tectal layers, while 
Fig. 1. Locations of injection sites in the OT. All injection sites are shown on the right side of the schematics for clarity of visualization. A Schematics showing location of neurobiotin injections at mid levels (upper schematic) and at rostral levels (lower schematic) of the OT. Black filled circles show injection sites in tadpoles, and white triangles show injection sites in postmetamorphic animals. Some symbols are displaced slightly for clarity. The photomicrograph (bottom image, dotted oval) shows the site of an iontophoretic injection of neurobiotin in deep layers of the OT in an adult bullfrog. Scale bar $=150 \mu \mathrm{m}$. B Schematics showing locations of PHA-L/CT $\beta$ injection sites at mid levels (upper schematic) and rostral levels (bottom) of the OT. Black filled circles show injection sites in tadpoles, white triangles show injection sites in postmetamorphic animals, and inverted gray triangles show locations of deep injection sites near the lateral edge of the TSl in 2 additional tadpoles. Projections from these 2 sites were overall similar to those from more shallow lateral OT injections, but with relatively greater label of auditory nuclei in the medulla and thalamus. The photomicrograph (bottom image, dotted oval) shows the site of a PHA-L/CT $\beta$ injection in mid layers of the OT in a stage 45 tadpole. Scale bar $=150 \mu \mathrm{m}$.

Fig. 2. Schematics of brain sections traced from our own in-house atlases of larval and postmetamorphic bullfrog brains using CorelDraw v. 12. For each schematic in $\mathbf{B}$ and $\mathbf{C}$, one side of the brain was drawn and then flipped so as to produce symmetrical sections. The top left insert shows the approximate caudal-torostral $(\mathrm{a}-\mathrm{g})$ level of each schematic on a horizontal sketch of the tadpole brain. Sections were cut at approximately the same rostral-caudal level in all brains. A Cresyl violet (left side) and schematic (right side) representation of nuclear boundaries in the brain of a tadpole in metamorphic climax (stage 43). The approximate position of the $\mathrm{mfb}$ and lfb in the thalamus (level f) is shown as dashed ovals. B Schematic representation of labeled cells (small filled circles), puncta (hatchmarked regions), and major fiber pathways (lines) following an injection into mid/deep layers
A

Neurobiotin

injection sites
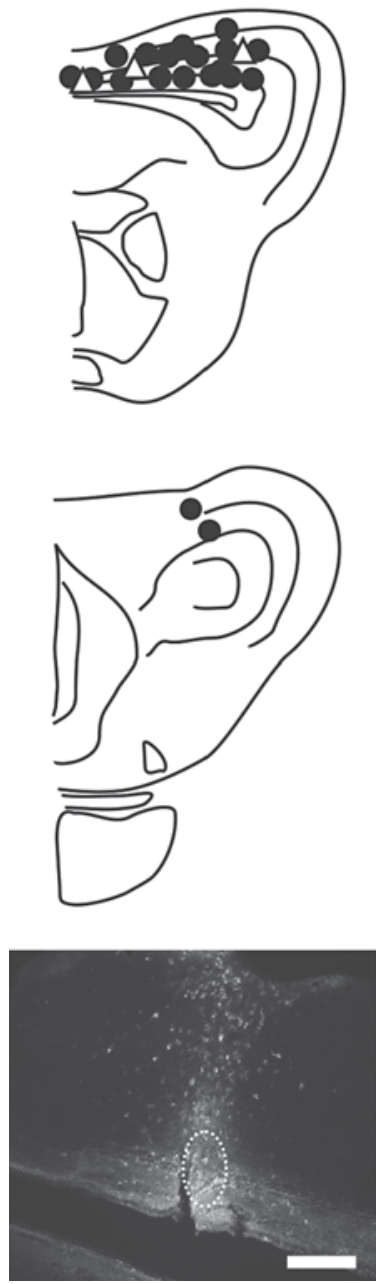

B

PHA-L/CT $\beta$ injection sites
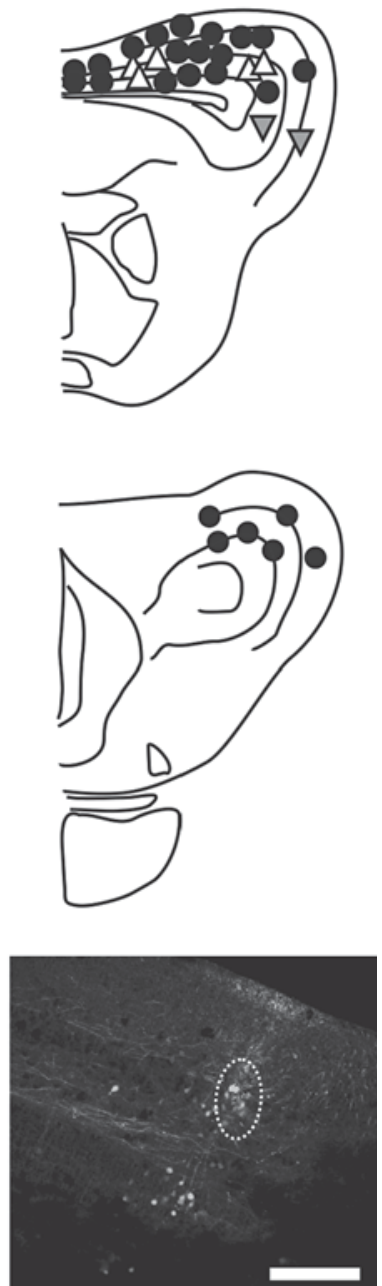

of the medial OT (large circle) in an early larval (stage 28) tadpole. The medullary lateral line region (LLa, LLnp) is indicated at level a. Note the more lateral position of the DMN at this stage compared to that in metamorphic climax. C Schematic representation of label following an injection into mid/deep layers of the medial OT (large circle) in a froglet. The relative density of the hatchmarked regions represents the degree of label (heavy $=$ densest hatchmarks; moderate $=$ medium hatchmarks; light $=$ sparsest hatchmarks). The injection sites in $\mathbf{B}$ and $\mathbf{C}$ were approximately the same size and extent. The data in $\mathbf{B}$ and $\mathbf{C}$ show the labeling for a representative animal in that developmental stage group. Intensity of label could vary from that shown in the tables, which depict most common ratings of label. Scale bars $=1 \mathrm{~mm}$. 


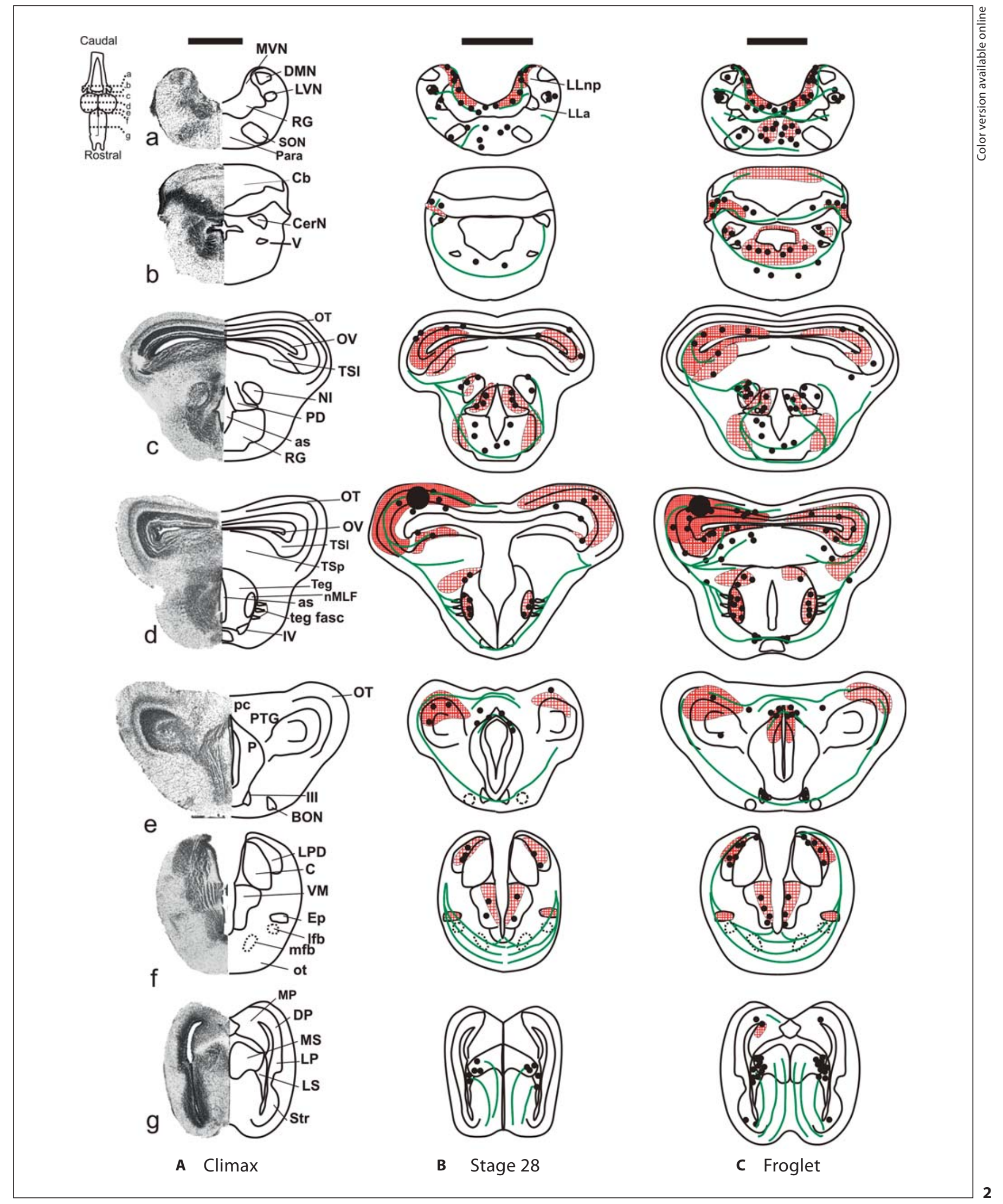

Development of Tectal Connectivity in

Brain Behav Evol 2010;76:226-247 
Fig. 3. Photomicrographs of neurobiotin-labeled fibers following injections into the medial OT of bullfrogs at different developmental stages. In all images, dorsal is up. A Hatchling (stage 24) tadpole. The injection site in superficial/mid layers is shown by the asterisk. The optic ventricle is closed in this image. There is dense cell label in the ipsilateral OT and in the dorsal tegmentum (Teg; arrowhead). Labeled fibers coursing towards the Teg are indicated by the arrow. Medial is to the right in this image. B Late larval (stage 41) tadpole, ipsilateral midbrain. Labeled fibers course laterally away from the injection site (in mid layers of the medial OT, not shown), and ventrally towards the tectobulbar tract (tbt) and medially towards the Teg and tegmental fasciculi (arrow). Fewer labeled fibers course towards and within the TS (doubleheaded arrow). Medial is to the right in the image. C Early larval (stage 30) tadpole. Labeled fibers course through the ipsilateral tegmental fasciculi (2 arrows) and the area near the interpeduncular nuclei (arrowhead) at the base of the midbrain. The asterisk indicates the midline of the brain. D Late larval (stage 41) tadpole, ipsilateral medulla. Medial is to the right in the image. Labeled fibers course through the dap (arrow), dorsally up to the MVN and laterally towards the LVN and DMN. A few scattered fibers are visible in the dorsal part of the LLnp (arrowhead). Fibers in the area of the descending trigeminal tract are heavily labeled (double-headed arrow). E Early larval (stage 30) tadpole. Fine fibers and terminals (arrow) are visible in the ipsilateral MVN. Medial is to the right in the image. $\mathbf{F}$ Late larval (stage 34) tadpole. The arrows show bilateral fiber label through the posterior commissure and the dorsal region of the posterior nucleus of the thalamus. The thalamic ventricle is shown by the asterisk. G Late larval (stage 37) tadpole. In the ipsilateral thalamus there is heavy label of the lateral optic tract (arrow) with fine fibers and terminals visible in the entopeduncular nucleus (arrowhead). Medial is to the right in this image. $\mathbf{H}$ Late larval (stage 34) tadpole. The optic chiasm (arrows) is labeled. The asterisk shows a fold in the tissue. Image shows the contralateral side of the brain. Medial is to the left. I Late larval (stage 41) tadpole. Label in the ipsilateral telencephalon, area of the medial forebrain bundle. Medial is to the right in the image. Fibers (arrow) and labeled cells in the medial septum (arrowhead, 1 cell is shown) are visible. Scale bars $=200 \mu \mathrm{m}($ A, B $), 150 \mu \mathrm{m}$ (C), $200 \mu \mathrm{m}$ (D), $50 \mu \mathrm{m}$ (E), $300 \mu \mathrm{m}$ (F), $50 \mu \mathrm{m}$ (G), $200 \mu \mathrm{m}$ (H), $50 \mu \mathrm{m}$ (I).
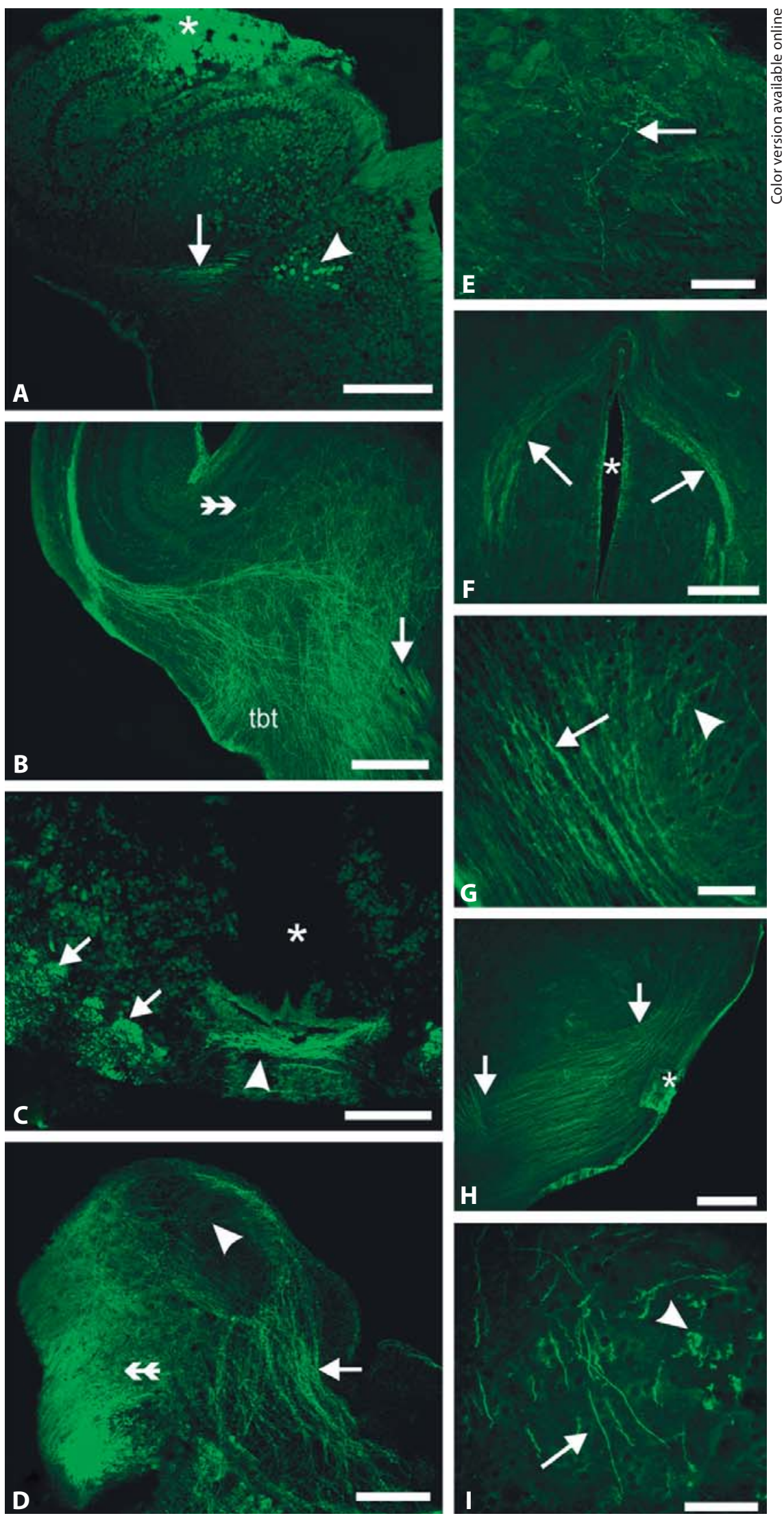
more superficial injections labeled more superficial fibers. Labeled fibers traveled from the injection site ventrally and laterally in a bundle to the lateral and ventral margins of the ipsilateralOT. Some of these fibers coursed medially towards the TSl and Teg and ventrally towards the tectobulbar tract (tbt; fig. 3B, stage 41). Putative boutons from these fibers, extending medially into the dorsal Teg, were also labeled. There was moderate to heavy fiber label along the lateral edges of the Teg and more laterally in and around the tegmental fasciculi (teg fasc; fig. 3C, stage 30). Labeled fibers decussated at the floor of the mesencephalon through and around the interpeduncular nuclei. Labeled fibers in the contralateral Teg, TS and OT varied in intensity from sparse in early larval animals to heavy in postmetamorphic animals.

Labeled tbt fibers traveled caudally, some terminating dorsally at the level of the NI and others progressing laterally and ventrally to the cerebellum $(\mathrm{Cb})$. There was moderate to heavy bilateral fiber label through the mesencephalic and medullary reticular gray (RG). Ipsilaterally, labeled fibers entered the medulla ventrally and laterally, coursing dorsally and medially through the SON and the paragigantocellular area to join the dorsal arcuate pathway (dap). Some labeled fibers also coursed through the ipsilateral ventral arcuate pathway (vap), eventually joining the heavily labeled ipsilateral descending trigeminal tract (fig. 3D, stage 41). dap fibers were moderately to heavily labeled across their entire medialto-lateral extent, passing through the abducens nucleus bilaterally. Near the ventral margin of the medial vestibular nucleus (MVN), dap fibers split into 2 pathways, 1 projecting through the MVN medially, and the other wrapping ventrally around the LLnp to terminate in the region of the lateral vestibular nucleus (LVN), with some extending to the region of the developing DMN (fig. 3D). After large, laterally-placed tectal injections, more extensive fiber label and putative nerve terminals could be traced to the DMN. Fiber label through the LLnp (in early and late larval animals only; the LLnp disappears during metamorphic climax) was sparse. Confocal images of neurobiotin label of the MVN region revealed many fibers and presumptive boutons terminating on or near cell bodies, suggesting that these fibers are inhibitory in nature (fig. 3E, stage 30).

At more rostral levels of the brain, neurobiotin injections into the OT resulted in moderate to heavy label of fiber segments and putative terminals in the PTG, posterior commissure (pc; fig. 3F, stage 34), dorsal part of the posterior $(\mathrm{P})$ thalamic nucleus, lateral optic tract (lot; fig. $3 \mathrm{G}$, stage 37 ), oc (fig. $3 \mathrm{H}$, stage 37 ), and the accessory optic tract. Tecto-thalamic fibers traveled in the lateral thalamic neuropil [medial to the regions of the corpus geniculatum and nucleus of Bellonci as defined in adult R. pipiens; Montgomery and Fite, 1991] bilaterally. Although labeled fibers coursed through the area of the basal optic nucleus (BON), there was no cell or puncta label visible in this nucleus. Labeled fibers and presumptive terminal boutons were observed in the lateral-posterior thalamus (LPD), at both anterior and posterior levels, and in the entopeduncular nucleus (Ep; fig. 3G). Some labeled fibers extended medially towards the anterior nucleus of the thalamus and more ventrally towards the ventromedial nucleus (VM) and the suprachiasmatic nucleus. In early larval stages, sparse label of the medial forebrain bundle $(\mathrm{mfb})$, extending up to the region of the medial septum (MS) and lateral septum (LS), was observed. Fiber label in the $\mathrm{mfb}$ increased to moderate in late larval (fig. 3I, stage 34) and metamorphic climax stages. The lateral forebrain bundle (lfb) is sparsely to moderately labeled throughout development, and is typically less intense than the $\mathrm{mfb}$.

\section{Bilateral Midbrain Cell Label is Observed throughout Development}

At all stages of development, injections of neurobiotin and of PHA-L/CT $\beta$ produced ipsilateral cell label in the OT in several sections rostral and caudal to the injection site (fig. 2, middle and right columns). Cell body label in the contralateral OT was also visible (fig. 4A-D, CT $\beta$ label), with intensity of label in tadpoles varying from sparse to moderate, depending on the size of the injection site. Contralateral OT label was more pronounced in tadpoles (fig. 4A-C) than in froglets (fig. 4D) or adults, even when comparing injections similar in locus and size. In the TS, cell label in the ipsilateral TSl varied from sparse in early larval animals to moderate at all other developmental stages. These labeled cells are mostly located in the most lateral extent of the TSl; more medially-located cells were found primarily directly ventral to the periventricular zone around the optic ventricle. Sparse cell body label in the lateral and ventral areas of the contralateral TSl was also typically present. Within the ipsilateral principal nucleus (TSp), labeled cells were sparse at all stages of development. More labeled cells were visible ventrally, near the border with the dorsal Teg. There was moderate to heavy cell body label in the ipsilateral nucleus of the medial longitudinal fasciculus (nMLF; fig. 4E-H) at all developmental stages. Labeled cell bodies were also visible in the contralateral TSp, Teg and nMLF, but typically at less intense levels than ipsilaterally. 

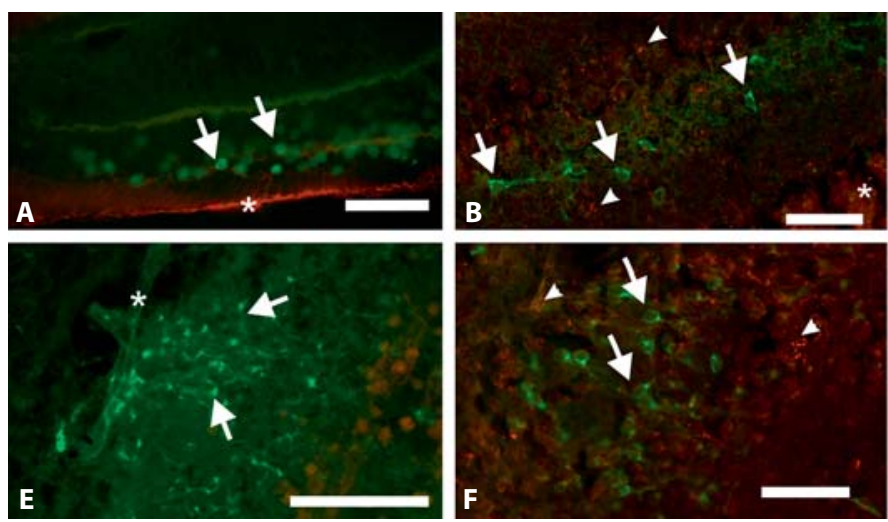

Fig. 4. PHA-L/CT $\beta$ label in the midbrain at different developmental stages. A CT $\beta$-labeled cells (arrows, 2 cells are shown) in deep layers of the contralateral OT of a stage 26 (early larval) tadpole. The injection was centered in deep layers of the ipsilateral OT. The periventricular layer is demarcated by an asterisk. B CT $\beta$-labeled cells (arrows, 3 cells are shown) and PHA-L-labeled puncta (arrowheads, 2 clusters of puncta are shown) in the contralateral OT of a stage 37 (late larval) tadpole. The injection site is shown in figure 6D. The periventricular layer is demarcated by an asterisk. C CT $\beta$-labeled cells (arrows, 2 cells are shown) and PHA-L-labeled puncta (arrowhead) in the contralateral OT of a stage 42 (metamorphic climax) tadpole. D Contralateral OT of a froglet. One CT $\beta$-labeled cell (arrow) is shown. The periventricular layer is demarcated by an asterisk. E-H Label in the ipsilateral nMLF at
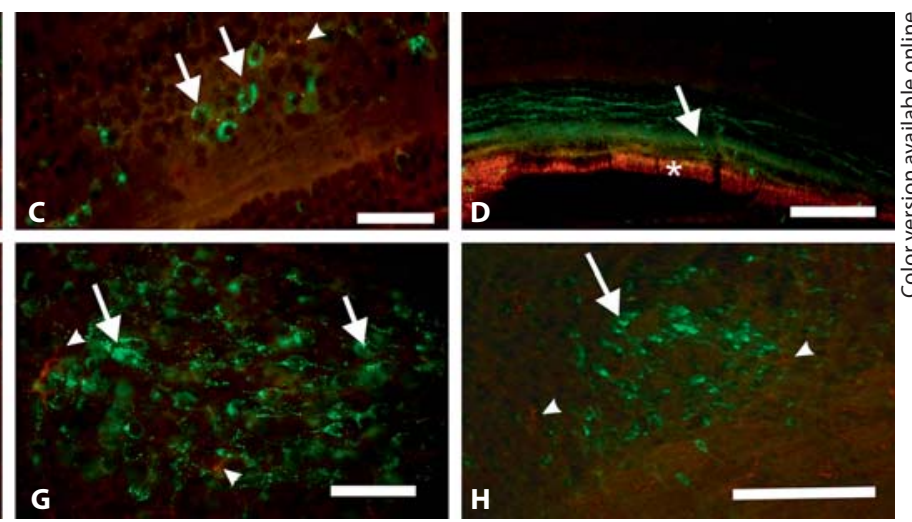

different developmental stages. E CT $\beta$-labeled cells (arrows, 2 clusters of cells are shown) in the ipsilateral MLF of a stage 31 tadpole. The asterisk indicates a blood vessel. Puncta in the nMLF are not visible at this magnification. F CT $\beta$-labeled cells (arrows, 2 cells are shown) and puncta (arrowheads, 2 clusters of puncta are shown) in the ipsilateral nMLF of a stage 37 tadpole (same brain as in B). G CT $\beta$-labeled cells (arrows, 2 cells are shown) and puncta (arrowheads, 2 clusters of puncta are shown) in the ipsilateral nMLF of a stage 42 tadpole (same brain as in C). H CT $\beta$-labeled cells (arrow) and puncta (arrowheads, 2 clusters of puncta are shown) in the ipsilateral nMLF of a froglet (same brain as in $\mathbf{D}$ ). In all images, dorsal is up. In $\mathbf{A}-\mathbf{D}$, medial is to the right; in $\mathbf{E - H}$, medial is to the left. Scale bars $=50 \mu \mathrm{m}(\mathbf{A}-\mathbf{C}), 200 \mu \mathrm{m}$ (D), 100 $\mu \mathrm{m}(\mathbf{E}), 50 \mu \mathrm{m}(\mathbf{F}, \mathbf{G}), 200 \mu \mathrm{m}(\mathbf{H})$.
The trochlear nucleus (IV) can be identified in early stage tadpoles as a thin streak of 10-20 spindle-shaped cells, distinct from the surrounding round-bodied cells, largely embedded in the lateral edge of the ventralmost region of the Teg. By metamorphic climax, the trochlear nucleus appears more circular in shape and has also become more discrete from the ventral tegmental region. Deep, lateral OT injections produce sparse retrograde cell label in this area, first appearing in late larval stages. Cell label in this area was qualitatively more intense in postmetamorphic animals.

\section{Connectivity with the NI Varies over Development}

The NI shows a gradual developmental progression in its cellular structure (fig. 5, top box), and its boundaries are difficult to demarcate in early larval brains. During this developmental period (stage 26), a somewhat circular (longest dimension $0.39 \mathrm{~mm}$ ) area comprised of a cell dense dorsal portion and a cell sparse ventral portion can be identified in the appropriate location in the caudal midbrain. A defined rim area, characteristic of the mature NI, cannot be reliably identified, and the medial margin of the NI is not clearly separable from the adjacent cell-rich nucleus posterodorsalis tegmenti mesencephali (PD) abutting the third ventricle. On the lateral margin, a line of cells serves to demarcate a cell-sparse area. By the middle of the late larval period (stage 36), the NI has achieved the characteristic ovoid shape seen in adult animals and its borders are now more easily demarcated from surrounding cell and fiber areas. The NI has doubled in its longest axis to approximately $0.78 \mathrm{~mm}$. It remains cell dense dorsally and medially, and more cell sparse ventrally, although cell density in the ventral area is greater than seen in early larval stages. The border (rim) region with the PD shows an outline 5-6 cells thick around its ventral edge, but this area is thicker dorsally and less distinct than that in adult frogs. The NI is easily identifiable in its shape and location during metamorphic climax stages, but is still more cell dense than in froglets. In froglets, overall cell density is reduced from that seen during larval stages, but the NI remains more cell dense than in adults. The rim border with the PD also is thicker than that in adults, particularly at its dorsal edge, but the lateral, dorsal and ventral borders are thin- 
ner than in tadpoles. In adult frogs, the longest dimension of the nucleus has increased to $1.05 \mathrm{~mm}$. Cell density has dropped markedly, cellular margins are thinner, and the rim border with the PD is clearly defined.

Along with these changes in cellular structure and nuclear boundaries, the trajectory and terminations of neurobiotin-labeled fibers from the tbt towards the ipsilateral NI also varied developmentally (fig. 5A-D). The major developmental trend was more extensive fiber label extending into the inner medullary core of the ipsilateral $\mathrm{NI}$, rather than being restricted to the borders of the nucleus. In early larval tadpoles, moderate fiber label was visible laterally and ventrally in the caudal midbrain, with sparser label extending medially towards the developing NI and heavier label extending more ventrally around the ventral border. Few labeled cells and terminals were visible within the inner medullary core. By the late larval period (fig. 5A, stage 32), labeled fibers were clearly visible extending into the ipsilateral NI, particularly from the dorsal/lateral direction, and along the lateral/ventral margins. Neurobiotin-labeled cells and terminals were visible both along the margins and within the nucleus. During metamorphic climax (fig. 5B, stage 45) and in froglets (fig. 5C), ipsilateral fiber label was heavier and showed more extensive arborizations within the inner medullary core of the NI. Terminal label was also visible. In adult animals (fig. 5D), there was consistent and extensive invasion of fibers into the inner medullary core, at levels qualitatively heavier than that seen in early and late larval animals.

Consistent with the data from neurobiotin injections, CT $\beta$ transport during tadpole development resulted in increasing numbers of labeled cells within the inner medullary core of the ipsilateral NI, rather than being limited to the borders. This trend did not clearly depend on the medial-lateral locus of the tectal injection site. At early larval stages (fig. 5E, stage 28), cell label was found mostly along and just within the dorsal borders of the NI, with fewer labeled cells within the inner medullary core. Between the late larval period and froglet stages (fig. 5G), labeled cells were more widespread in distribution, consistently appearing both along the borders of the nucleus as well as within the inner medullary core. The heaviest concentration of labeled cells was visible in the PD adjacent to the developing rim area. At all developmental stages, PHA-L-labeled puncta (table 3; fig. 5E) were observed within the ipsilateral NI.

Contralaterally, sparse to moderate fiber label, depending on the size of the injection, was observed around the lateral and ventral margins of the NI, beginning in the early larval period. As on the ipsilateral side, heavier fiber label was observed in the PD than in the NI, particularly at these early developmental stages. Sparse CT $\beta$ cell body label was visible around the dorsal and lateral margins of the contralateral NI (fig. 5F, stage 28). By metamorphic climax, more cells began to appear within the inner medullary core, although the intensity of label was consistently less than that on the ipsilateral side. In froglets (fig. $5 \mathrm{H}$ ), labeled fibers were visible passing through and around the contralateral NI. These fibers likely represent axons of the contralateral isthmotectal cells. There was no evidence of labeled puncta within the contralateral NI at any developmental stage. Moderate to heavy cell label and sparse puncta label were consistently present in the neighboring PD.

\section{Cerebellotectal Projections Expand over Larval Development}

At all developmental stages, neurobiotin-labeled fibers and fiber segments coursed through the mesencephalic RG around and through the ipsilateral cerebellar nucleus (CerN) and up to the $\mathrm{Cb}$. CT $\beta$-labeled cell bodies were observed in the CerN and in the lateral $\mathrm{Cb}$ (auricular lobe as defined by Uray and Gona [1999]; fig. 6). In early larval animals, sparse cell body label was visible in the ventral part of the ipsilateral auricular lobe (fig. 6A, stage 28). At these stages, cells are small and undifferentiated, but their location suggests that they are in the developing granular layer. Sparse cell label was visible in the ipsilateral CerN. The only visible puncta label in the $\mathrm{Cb}$ occurs adjacent to the periventricular layer; no puncta label was seen in the CerN. In later stages of the late larval period (fig. 6B, C, stage 37; injection site shown in fig. 6D), moderate levels of labeled cells are visible in the ipsilateral granule layer, extending laterally to medially towards the midline (fig. 6B). Contralateral cell body label, in the same relative locations, was also present (fig. 6C). Neurobiotin-labeled fibers were visible spreading lateral to medial in the developing granular layer (fig. 6E, stage 41). During metamorphic climax and throughout postmetamorphic life, cell label in the $\mathrm{Cb}$, in the same relative locations as in metamorphic climax, was visible bilaterally. In adults, small labeled cells were visible bilaterally in the region of the auricular lobe, but also more dorsally, in the corpus cerebelli (terminology of Uray and Gona [1999]; fig. 6F, G). Cell label was somewhat more extensive on the ipsilateral than on the contralateral side. Because the dendritic arbors of these cells were not filled, we could not reliably determine their morphology. Label in the CerN was qualitatively less in the postmetamorphic period than in tadpoles. 
Fig. 5. Nucleus isthmi (NI) organization and label across development. The top box shows cresyl violet-stained sections of the NI at 4 different developmental stages (stage 26, stage 36, froglet, adult). The dorsal border of the NI becomes more defined across development, and cell density decreases. Dorsal is up and medial to the right in these images. Scale bars $=200 \mu \mathrm{m}$. A-D Neurobiotin label in the ipsilateral NI at 4 different developmental stages. Dorsal is up and medial to the right in these images. A Late larval (stage 32) tadpole. Injection site is in deep tectal layers. The asterisk indicates a hole in the tissue. A cluster of labeled fiber segments and putative terminals (arrowhead) is visible in the dorsal NI. The arrow points to labeled fiber segments at the ventral border. The double-headed arrow points to labeled fiber segments in the PD. B Metamorphic climax (stage 45) tadpole. The asterisk indicates a hole in the tissue. Labeled fibers (arrows) course into the NI both from the lateral edge and also from the dorsal margin (double-headed arrow). C Froglet. Neurobiotin-labeled fibers enter the NI from the lateral and dorsal margins (arrows) and form a dense cloud of terminations. Two labeled cells are shown (arrowheads). The doubleheaded arrow shows labeled fibers in the PD. D Adult frog. High-power image of fiber arborization and terminals in the inner medullary core of the NI. E-H PHA-L/CT $\beta$ label in the ipsilateral and contralateral NI at 2 different developmental stages. E Label in the ipsilateral NI of an early larval (stage 28) tadpole. The injection site is schematized in figure $2 \mathrm{~B}$. Labeled cells are indicated by arrows ( 4 cells are shown). The arrowhead shows a cluster of puncta. Dorsal is up and medial is to the right in this image. $\mathbf{F}$ Label in the contralateral NI of the same stage 28 tadpole. Labeled cells along the dorsal margin are indicated by the arrows ( 2 cells are shown). Dorsal is up and medial is to the left in this image. G Label in the ipsilateral NI of a froglet. Arrows indicate clusters of labeled cells. Labeled fiber segments extending into the NI are shown by the doubleheaded arrows. The arrowhead demarcates label in the PD. The asterisk shows the periventricular zone at the midline of the brain. Dorsal is up and medial is to the right in this image. $\mathbf{H}$ Label in the contralateral NI of the same froglet. The asterisk indicates the aqueduct of Sylvius. Labeled cells in the NI are shown by the arrows ( 2 cells are shown). The double-headed arrow demarcates labeled fibers passing through the NI. The arrowhead demarcates label in the PD. Dorsal is up and medial to the left in this image. Scale bars: = $200 \mu \mathrm{m}(\mathbf{A}-\mathbf{C}), 50 \mu \mathrm{m}$ (D), $50 \mu \mathrm{m}$ (E, F), $100 \mu \mathrm{m}$ $(\mathbf{G}, \mathbf{H})$.

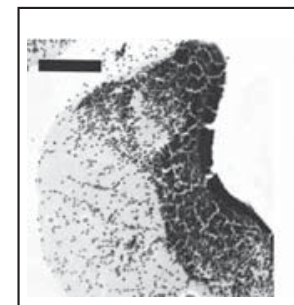

stage 26
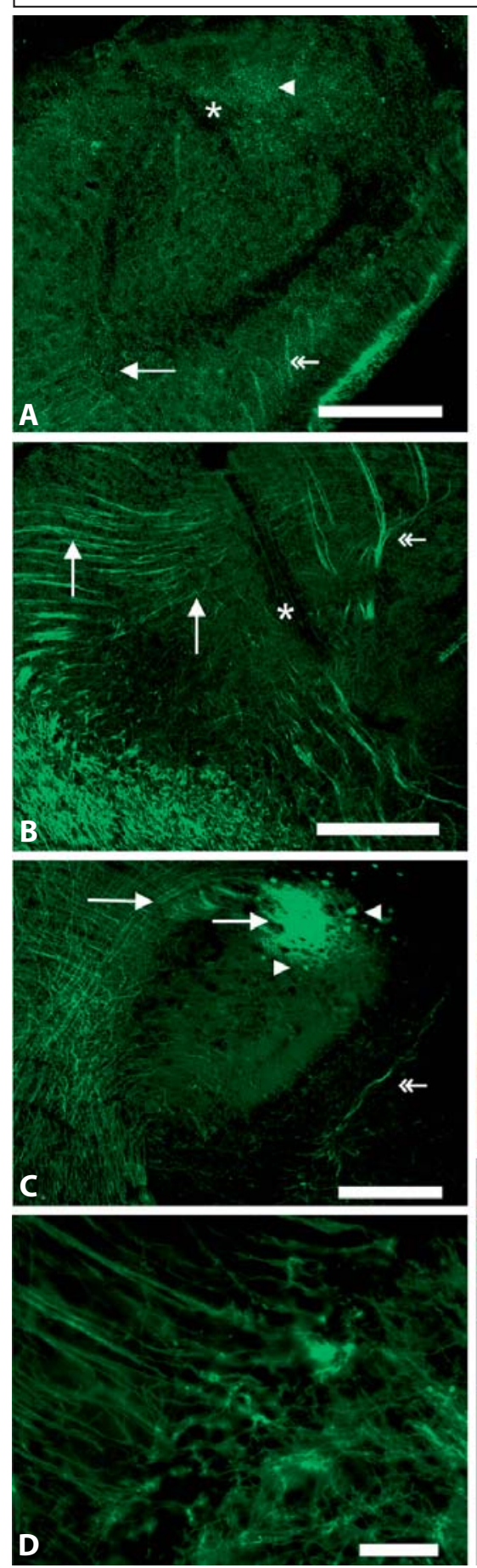

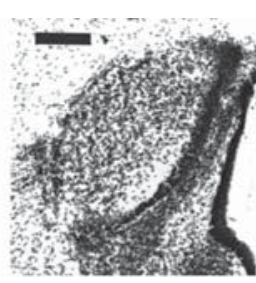

froglet
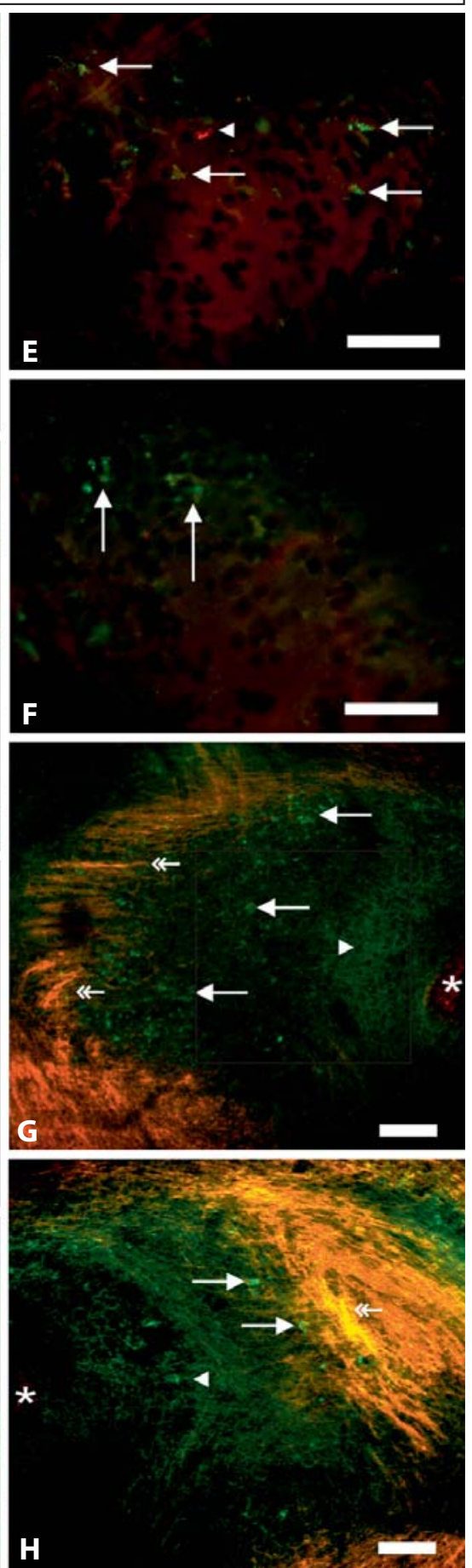
There was moderate to heavy bilateral fiber label in the $R G$ ventral to the $\mathrm{Cb}$, coursing through the region of the trigeminal nucleus, at all developmental stages. Cell bodies in the RG were also consistently labeled, both ipsilaterally and contralaterally. No cell label was observed in the trigeminal nucleus during early larval stages, with sparse label appearing near the middle of the late larval period. No puncta label was observed in the trigeminal nucleus at any developmental period.

\section{The Auditory and Vestibular Medulla Project to the OT}

Considerable cell and puncta label were visible in the dorsal medulla at all stages of development (tables 2, 3). PHA-L/CT $\beta$ injections into the OT consistently produced moderate to heavy retrograde cell filling and puncta/fiber label in the mesencephalic and medullary RG bilaterally. Sparse label of cell bodies was seen in and around the developing abducens nucleus.

CT $\beta$-labeled cells and PHA-L-labeled puncta were present both ipsilaterally (fig. 7A, B) and contralaterally in the MVN. These labeled cells were usually round in shape with diameters in the 15-20 $\mu \mathrm{m}$ range, and were easily distinguished from the larger (30-35 $\mu \mathrm{m}$ diameter) polygonally-shaped labeled cells found more laterally and ventrally in the LVN (fig. 7A, C). MVN and LVN cell label persisted throughout larval and postmetamorphic life, with somewhat heavier label in the LVN. Puncta label was pronounced in the MVN, but was not visible in the LVN at any developmental stage. During early and late larval stages, CT $\beta$ label was observed bilaterally in small (20 $\mu \mathrm{m})$ bipolar, spindle-shaped cells in the ipsilateral lateral line nucleus (LLa; fig. 7B). This label disappeared entirely during metamorphic climax. During later stages of the late larval period and throughout metamorphic climax, scattered CT $\beta$-labeled cells were visible around the dorsal and lateral borders of the ipsilateral DMN (fig. 7A), but only after lateral OT injections. In general, more cell body label appeared in the DMN after very large, lateral injections that impinged upon the lateral TSl.

At all developmental stages, injections centered in mid or deep layers of the OT resulted in sparse label of small $(15-20 \mu \mathrm{m})$ oval cells in the ipsilateral SON (fig. 7D), primarily around its medial border with the adjacent paragigantocellular area and its dorsal border with the medullary RG. Puncta label within the SON was absent, although sparse puncta were visible in the vap. No cell body or puncta label was seen in the contralateral SON. More extensive label of the ipsilateral SON was seen after more lateral OT injections. Regardless of medial-lateral locus of the injection site, moderate label of large (30-40 $\mu \mathrm{m})$ cells throughout the paragigantocellular area bilaterally (table 2) and light to moderate label of fiber segments in the vap were consistently observed.

\section{Tectal-Forebrain Connections}

The extent of retrograde CT $\beta$ cell body label in the thalamus was relatively consistent across development (table 2). There were no reliable differences in locus and extent of cell body label in thalamic nuclei related to medial/lateral position of the OT injections. Cell body label in the LPD, P, and VM nuclei was typically sparse in early larval animals, but increased to moderate in late larval stages and remained at that level up to adult stages. Label was typically of similar intensities ipsilaterally and contralaterally. There was no cell body label in the Ep at any developmental stage. Sparse cell body label in the ipsilateral anterior nucleus was visible beginning in metamorphic climax and extending into the postmetamorphic period. Beginning in metamorphic climax, sparse bilateral CT $\beta$ label of cell bodies was visible in the oculomotor nucleus (III). This label increased to moderate in froglets and adults.

Similar to the results of neurobiotin transport, the densest PHA-L fiber and terminal label (moderate in late larval animals, heavy in older animals) was found in the pc, OT, oc, and the lateral thalamic neuropil. Puncta label was visible bilaterally in the Ep, LPD and VM at all stages of development (table 3). Puncta label in the ipsilateral anterior thalamus was first visible during late larval stages and contralaterally during metamorphic climax.

Tadpole brains showed consistent label in both the MS and the LS bilaterally (fig. 8A, stage 31), with no clear differences in extent of label related to medial/lateral locus of the tectal injection. In early stage tadpoles and in the beginning of the late larval period (fig. 8A), labeled cells in the MS were round-bodied and about $10-15 \mu \mathrm{m}$ in diameter, and located close to the periventricular zone of the lateral ventricle. Label increased to moderate during the late larval period, during metamorphic climax, and in froglets (fig. 8B), and, instead of being concentrated around the periventricular zone, extended across the medial-to-lateral extent of the MS. In adult frogs, label was sparser and again confined to the cell region directly adjacent to the periventricular zone. Cell body label in the LS varied from sparse to moderate across development (fig. 8C, subadult). Scattered labeled cells were observed bilaterally in the medial pallium (MP), beginning in the late larval period (fig. 8D, stage 37). Cell body label in the dorsal pallium (DP) was inconsistent, and that in the ven- 

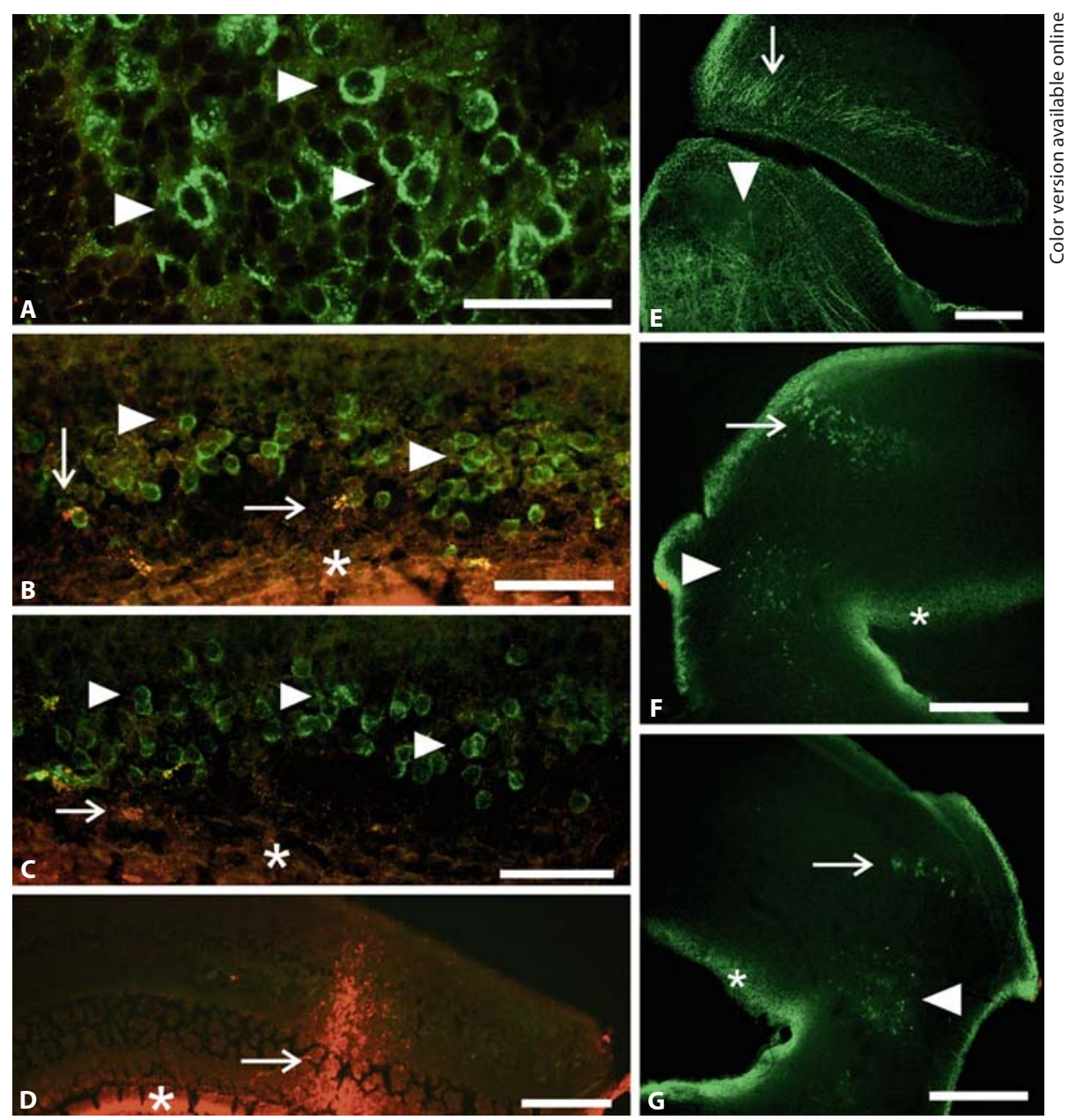

Fig. 6. Cell, puncta and fiber label are visible in the $\mathrm{Cb}$ after injections of PHA-L/CT $\beta$ (A-D) or neurobiotin (E-G) in the OT. In all images, dorsal is up. A Early larval (stage 28) tadpole. The injection site is shown in figure 2 , level $\mathrm{d}$, middle column. CT $\beta$-labeled cells (arrowheads, 3 cells are shown) are visible in the ipsilateral lateral/ventral $\mathrm{Cb}$ (auricular lobe), close to the periventricular layer. No puncta label is visible outside of the periventricular layer. B Late larval (stage 37) tadpole. CT $\beta$-labeled cells (arrowheads, 2 cells are shown) in the ipsilateral ventral $\mathrm{Cb}$, extending more medially than in $\mathbf{A}$. The periventricular layer is indicated by the asterisk. Puncta label is visible (arrows). C Contralateral Cb of the same animal as in B, same level of the Cb. CT $\beta$-labeled cells (arrowheads, 3 cells are shown), also extending more medially than in A. Scattered puncta label is visible (arrow). The asterisk demarcates the periventricular layer. In this animal, intensity of ipsilateral and contralateral $\mathrm{Cb}$ cell label was qualitatively similar, although in younger animals in the late larval period, label was qualitatively less intense on the contralateral side. D Injection site from which data in $\mathbf{B}$ and $\mathbf{C}$ were obtained. The injection site (arrow) is centered in deep layers of the medial OT, with some spread of PHA-L into the periventricular layer (asterisk). E Neurobiotinlabeled fibers in the ipsilateral $\mathrm{Cb}$ (arrow) and extending to the CerN (arrowhead) of a late larval (stage 41) tadpole, following injection into mid layers of the medial OT. F CT $\beta$-labeled cells in the ipsilateral $\mathrm{Cb}$ (corpus cerebelli, arrow) and in the auricular lobe (arrowhead) of an adult bullfrog after injection in deep layers of the medial OT. The injection site is shown in figure 1B. The asterisk demarcates the periventricular layer. G Contralateral $\mathrm{Cb}$ in the same brain section shown in $\mathbf{F}$. Cell body label in the corpus cerebelli (arrow) and auricular lobe (arrowhead) is visible, but somewhat less extensive than on the ipsilateral side. The asterisk demarcates the periventricular layer. CT $\beta$-labeled cells in the $\mathrm{Cb}$ are qualitatively less numerous than on the ipsilateral side. In $\mathbf{A}$, B, D-F, medial is to the right. In $\mathbf{C}$ and $\mathbf{G}$, medial is to the left. Scale bars $=50 \mu \mathrm{m}(\mathbf{A}-\mathbf{D}), 200 \mu \mathrm{m}(\mathbf{E}-\mathbf{G})$. 
tral striatum visible only after completion of metamorphic climax.

Fiber projection pathways to the telencephalon as indexed by PHA-L were highly discrete and very limited. Light label of fiber pathways was observed through the preoptic area bilaterally. There was no consistent puncta label in either the MS or LS at any stage of development. Sparse puncta label was observed ipsilaterally in the MP (table 3), beginning during the late larval period.

\section{Discussion}

Our data identify anatomical substrates underlying visual behaviors in both larval and postmetamorphic bullfrogs, and they are consistent with models of visuomotor behavior [Ewert et al., 1983] suggesting that the anuran OT is a crucial part of a complex circuit regulating orienting behaviors triggered by input from several sensory modalities, including the visual, vestibular, auditory, and somatosensory. Refinement of this complex circuitry occurs over the metamorphic transition from aquatic to aerial vision, in advance of or coincident with the appearance of the new behavioral output that occurs in the postmetamorphic period. These neuroanatomical changes occur along with peripheral morphological changes including the emergence and differentiation of hindlimbs during the late larval period, the emergence and differentiation of forelimbs during metamorphic climax, the degeneration of the lateral line neuromasts, dorsal migration of the eyes, and appearance of the nictitating membrane during climax, and the emergence of the external tympanum early in the froglet period. Together, these morphological and neuroanatomical events provide the basis for the more complex visuomotor behaviors of postmetamorphic frogs.

Major ascending and descending tectal projection pathways to the thalamus, Teg, and rhombencephalon are consistent in their trajectories across the entire developmental span from early larval tadpoles to adults. The main trends observed in these patterns of projections are an increase in intensity of label and changes in the distribution of label. In early larval stages, the developing OT receives input from medullary nuclei subserving auditory, vestibular and lateral line functions (MVN, LVN, and LLa). Afferent projections from the LLa disappear during metamorphic climax, consistent with the degeneration of the peripheral lateral line neuromasts during this developmental time, but connectivity with the vestibular medulla remains stable across development. At all develop-

Development of Tectal Connectivity in Bullfrogs mental stages, the OT receives input from the medullary RG, paragigantocellular area, TSl, Teg, nMLF, and various thalamic nuclei (LPD, P, VM). Other patterns of afferent input, including those from the NI, Cb, TSp, and telencephalic nuclei are more developmentally variable in intensity, extent and distribution of label. Tectal efferents to the RG, MVN, NI, LPD, VM, and Ep are stably present across development, varying only in intensity of label. Other efferent pathways, to the LLnp, Cb, TS, and medial pallium, show more developmental variability.

\section{Technical Considerations}

Our results are based on comparisons of data obtained by 3 different tracers - neurobiotin, PHA-L, and CT $\beta$ that have not been widely used in previous studies of anuran neuroanatomy. These tracers may identify projections not visible with horseradish peroxidase [HRP; Luppi et al., 1995], which has been the most commonly used tracer for identifying neuroanatomical projections in adult frogs [R. pipiens: Wilczynski and Northcutt, 1977; Grobstein and Comer, 1983; Masino and Grobstein, 1990; Montgomery and Fite, 1991; R. esculenta, R. ridibunda: Lazar et al., 1983; X. laevis: Zittlau et al., 1988]. Yet, many of the projections that we identified in adult bullfrogs using these tracers are consistent with those previously observed based on transport of HRP. We also observed in our sample of adult bullfrogs some patterns of connectivity not previously reported in other species of adult anurans. Some of this variability may be the result of species differences. Other factors include the more rapid and long-distance transport of neurobiotin compared to HRP [Jacquin et al., 1992], as well as the ability of neurobiotin to label trans-neuronally [Huang et al., 1992]. The use of confocal optics in our analysis may also have uncovered projections not visible with older optical systems. Because neurobiotin travels in both anterograde and retrograde directions, and because both PHA-L and CT $\beta$ may be transported bidirectionally through fibers of passage damaged by the injection process [Cliffer and Giesler, 1988; Chen and Aston-Jones, 1995], some of our injections may have labeled fibers of passage or collaterals of retrogradely labeled cells. We addressed these possible interpretational difficulties by comparing results from all 3 tracing methods, and by examining the distribution of labeled cell soma and puncta associated with labeled fibers.

Although we attempted to deposit criterion amounts of tracer in all brains, there was inevitably some variability in the size of injection sites. Within a particular stage group, larger injections typically produced more intense 
Fig. 7. Label of the ipsilateral medulla following PHA-L/CT $\beta$ injections into the medial OT at different developmental stages. A Metamorphic climax (stage 42) tadpole. Injection site is in deep tectal layers. There is heavy fiber label in the MVN (doubleheaded arrows), and moderate cell and fiber label in the RG. Arrowheads point to labeled cells in the LVN. A few scattered labeled cells are visible around the borders of the DMN (arrow). B CT $\beta$-labeled cell (arrow, 1 cell is shown) in the ipsilateral LLa of a stage 28 tadpole. Labeled cells in the MVN are indicated by the doubleheaded arrow. Clusters of puncta in the LLnp and the MVN are indicated by arrowheads. C High power images of labeled cells (arrows, 2 cells are shown) in the LVN of a stage 41 (metamorphic climax) tadpole (same animal as shown in A). D Cell label (arrow, 1 cell is shown) in the ipsilateral SON of a late larval (stage 37) tadpole. Scale bars $=150 \mu \mathrm{m}(\mathbf{A}), 50 \mu \mathrm{m}$ (B-D). In all images, dorsal is up and medial is to the right.

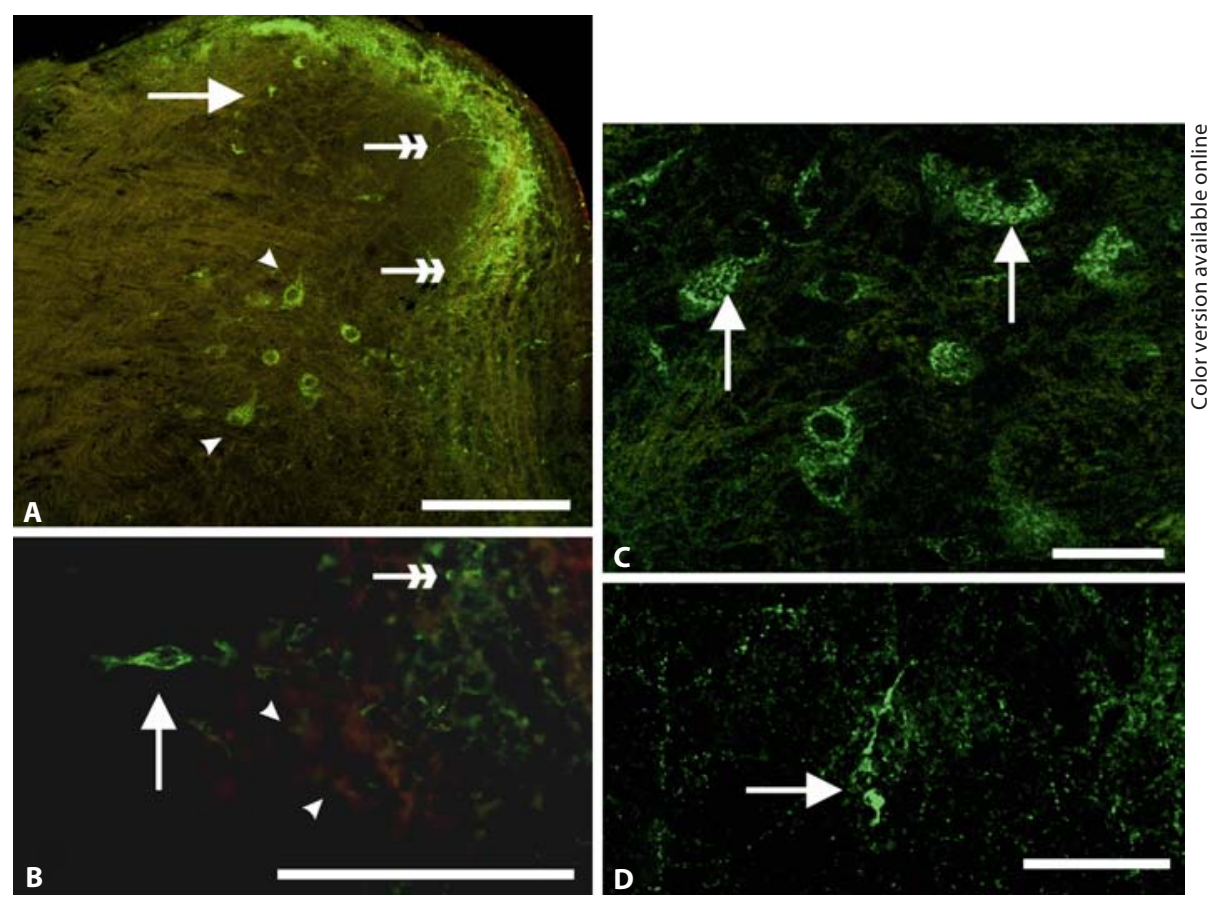

and qualitatively greater label, but, unless these larger injections spread into the lateral TS, they did not reveal new target zones unlabeled by smaller injections. Control injections, of the same size as used for the OT injections, limited to the TS produced no label of extraocular nuclei, lot, oc, or the telencephalon [see also Horowitz et al., $2007 \mathrm{~b}]$. Some very large injections were deliberately made in order to assess any tracer leakage. Large injections that spread into the TS resulted in greater intensity and distribution of label in the DMN, SON, Cb, posterior thalamic nucleus, and central thalamic nucleus. Large pressure or iontophoretic injections directly into the choroid plexus or the optic ventricle, also performed as control experiments, resulted only in label of the membranes overlying the brain or in the periventricular zones. We considered any periventricular PHA-L label present in our data to be the result of tracer leakage, and we did not consider this label in our results.

Most of our injection sites were centered in mid and deep, rather than superficial, tectal laminae, and we did not observe any consistent differences in afferent or efferent connectivity on the basis of laminar position of injection. The developmental variability in tectal lamination [Horowitz and Simmons, 2007] prevented restricted injections to any individual layer. Our results are based primarily on injections placed at mid-levels of the OT; we performed very few injections centered at very rostral lev- els of the OT, and we made no injections at caudal levels of the OT. It is possible that injections restricted to these levels may uncover further developmental variability in tectal connectivity. Moreover, because we did not systematically vary rostral-caudal site of injection, our data do not address issues of topography.

\section{Species and Developmental Variability in Tectal \\ Brainstem Projections}

Projections from the OT to the ipsilateral TS and Teg have been described previously in developing [Debski and Constantine-Paton, 1993] and adult R. pipiens [Wilczynski and Northcutt, 1977; Hofmann et al., 1990; Masino and Grobstein, 1990; Montgomery and Fite, 1991] and in developing [Chahoud et al., 1996] and adult X. laevis [Zittlau et al., 1988]. Our data confirm that a similar pattern of projections is present in early stage bullfrog tadpoles, and remains developmentally stable. We observe more labeled cells in both the ipsilateral and contralateral TSl and in the Teg, particularly in the nMLF, than reported in adult $R$. pipiens. We note, however, that even the several experiments describing HRP transport in that species do not all agree on the relative intensity and extent of some tectal projections. For example, both Hofmann et al. [1990] and Masino and Grobstein [1990] report more extensive HRP label of the ventral midbrain (Teg, nMLF) than observed by Wilczynski and Northcutt [1977]. 

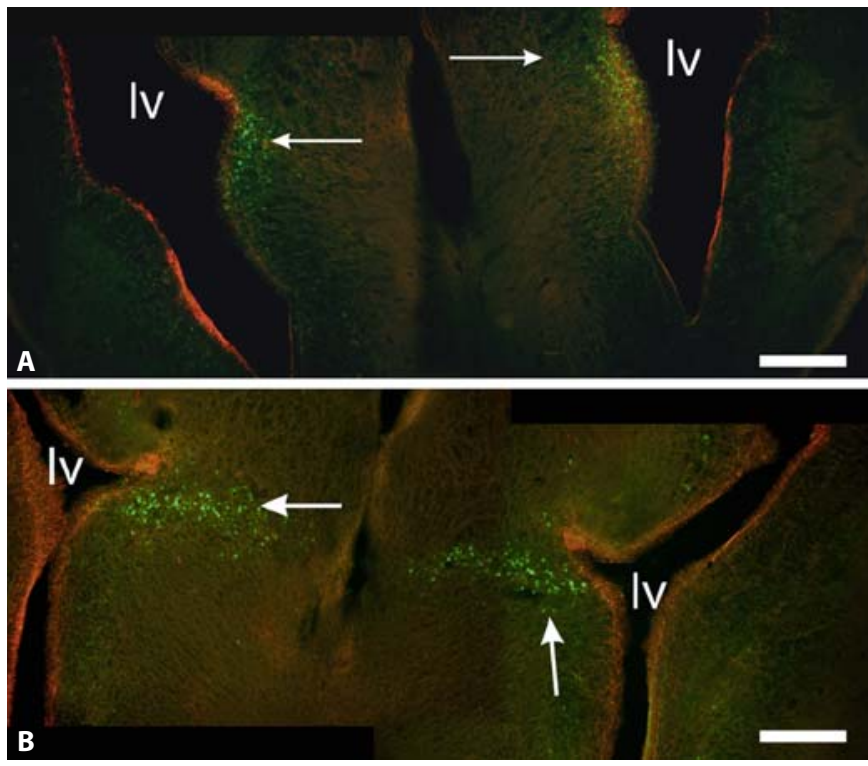

Fig. 8. CT $\beta$-labeled cells in the telencephalon following tracer injection into the medial OT. A Images of the ipsilateral (left side of the image) and contralateral (right side of the image) of the telencephalon of a late larval (stage 31) tadpole. Arrows point to clusters of labeled cells in the medial septum on both sides of the brain. No puncta label outside of the periventricular layer is present. lv = Lateral ventricle. $\mathbf{B}$ Images of the ipsilateral (left side of the image) and contralateral (right side of the image) of the telen-

Our data show neurobiotin and CT $\beta$ cell label in the contralateral OT of both larval and adult bullfrogs. This label is moderate in tadpoles, but decreases to sparse in adults. Analyzing deposits of rhodamine beads, Debski and Constantine-Paton [1993] observed 'few' retrogradely labeled cells in the contralateral OT of juvenile $R$. pipiens (the extent of such projections in tadpoles could not be assessed in that study, as only bilateral OT injections were performed in those animals). Masino and Grobstein [1990] observed 'two to eight' HRP-labeled cells in the contralateral OT after multiple injections into the ipsilateral OT in adults of that species, while neither Wilczynski and Northcutt [1977] nor Montgomery and Fite [1991] reported any HRP-labeled contralateral cells. No tectaltectal projections were observed in either larval or adult Xenopus [Zittlau et al., 1988; Chahoud et al., 1996]. Because our injections were smaller in size than the HRP
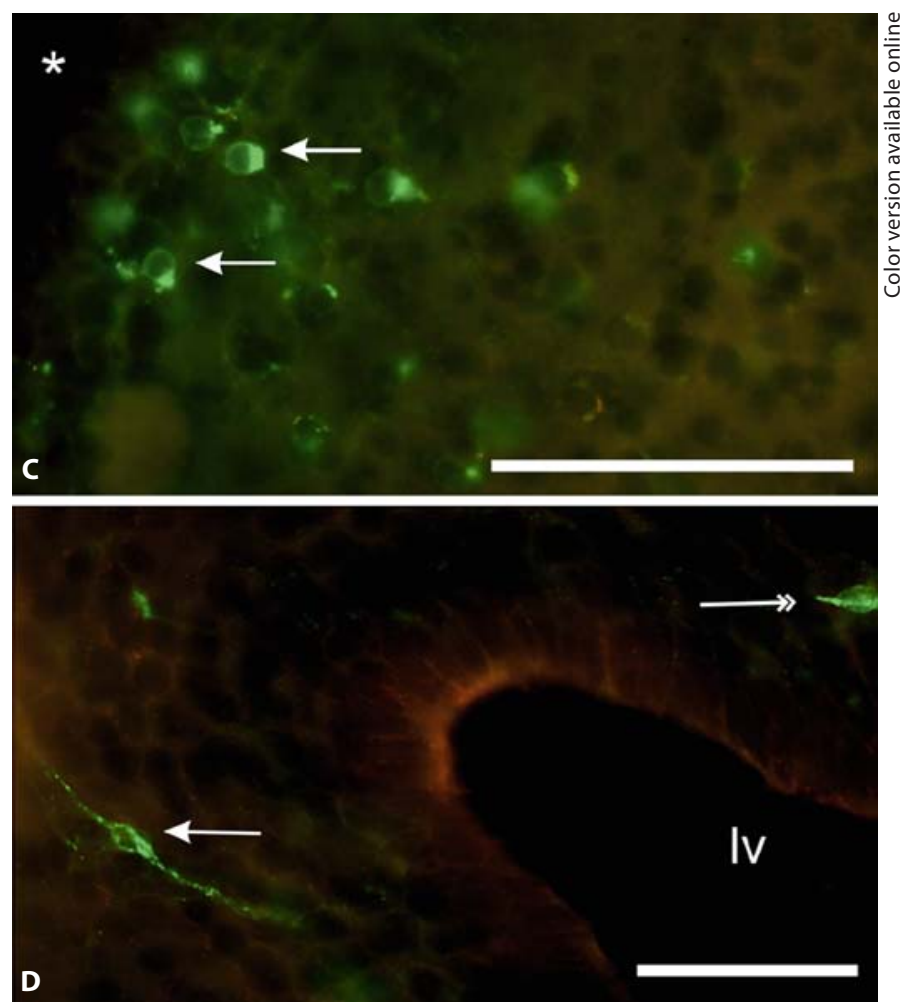

cephalon of a froglet. Arrows point to clusters of labeled cells in the medial septum on both sides of the brain. C Labeled cells (arrows, 2 cells are shown) in the lateral septum of a subadult frog. The asterisk shows the location of the lv in this section. D Labeled cell (arrow, 1 cell is shown) in the ipsilateral medial pallium of a stage 37 tadpole. The double-headed arrow demarcates 1 labeled cell in the dorsal pallium. Scale bars $=200 \mu \mathrm{m}(\mathbf{A}, \mathbf{B}), 50 \mu \mathrm{m}(\mathbf{C}$, D).

injections in these other studies, it is unlikely that these discrepancies reflect leakage of tracer. We suggest, instead, that differences in intensity of contralateral OT label reflect both species and developmental differences.

Our data also show both similarities and differences in the structure of the NI and its connectivity with the OT compared with previous reports in other anuran species. We confirm previous work [Dann and Beazley, 1982; Debski and Constantine-Paton, 1993] showing that the tadpole's NI undergoes a delayed maturation. In both $R$. pipiens and Limnodynastes, a distinct rim area, which serves to demarcate the boundaries of the adult NI, does not appear until the end of the late larval period or beginning of metamorphic climax [Dann and Beazley, 1982, 1990; Grobstein and Comer, 1983]. The rim area of the NI in adult $R$. pipiens projects to binocular areas of the OT [Grobstein and Comer, 1983]. The late appearance of the 
rim area in bullfrog tadpoles is consistent with the limited binocular field of these animals; its more distinct appearance during metamorphic climax occurs at about the same time as the onset of the dorsal migration of the eyes, and prior to the subsequent broadening of the binocular field of froglets. This delayed morphological maturation makes comparative analysis of afferent and efferent projections of the NI in different anuran larva problematic, as interpretation of results may depend on different definitions of the boundaries of this changing nucleus.

Analyses of the development of the tecto-isthmal-tectal projections in both Xenopus and Limnodynastes tadpoles suggest that these pathways are present during early larval life (Nieuwkoop/Faber stages 51-55, where metamorphic climax is stage 66) [Dann and Beazley, 1982, 1990; Udin and Fisher, 1985; Chahoud et al., 1996]. In bullfrog tadpoles, the ipsilateral isthmotectal and tectoisthmal projections are visible during early larval stages (Gosner stages 25-30), broadly consistent with the timing observed in these other tadpole species. Results of neurobiotin fiber label suggest that fibers enter the ipsilateral NI from 2 different directions, 1 laterally and ventrally and the other from a more dorsal direction, consistent with previous reports in Limnodynastes [Dann and Beazley, 1990]. Finally, as expected, we observed no puncta label within the contralateral NI at any developmental stage; the fiber label we observed around and passing through the contralateral NI is likely label of isthmotectal fibers. Our results differ from those reported in other species of larval anurans primarily in the distribution of labeled cells within the NI. During early larval stages in the bullfrog, cell body label in both the ipsilateral and contralateral NI was typically concentrated around the margins of the nucleus. As development proceeds, more labeled cells appear within the inner medullary core of the NI. Such a trend was not reported in Limnodynastes [Dann and Beazley, 1982, 1990], where the position of labeled cells on the ipsilateral side was more widespread even in equivalent early larval stages. Those results likely reflect the placement of the injection in the OT. Because we did not set out to trace the development of topography, we did not systematically vary the rostral-caudal location of the tectal injection. Differences between studies in distribution of label in the NI can also be attributed to differences in tracer properties, differences in size of tectal injection sites, differences in location of tectal injection sites, and differences in survival time.

Projections between the $\mathrm{Cb}$ and the OT have not been described in either adult $R$. pipiens [Wilczynski and Northcutt, 1977; Hofmann et al., 1990; Masino and Grob- stein, 1990] or X. laevis at any developmental stage [Zittlau et al., 1988; Chahoud et al., 1996]. Our finding of connectivity between the $\mathrm{OT}$ and $\mathrm{Cb}$ at all developmental stages may reflect the use of more sensitive tracers, or a species difference. Label in the $\mathrm{Cb}$ was detected using both neurobiotin, which travels transneuronally, and PHA-L/CT $\beta$, which do not. Efferent projections from the $\mathrm{Cb}$ to the OT have also been observed in adult goldfish, Carassius auratus [Ikenaga et al., 2002]. In several species of adult mammals [May, 2006], there are direct projections from the ipsilateral fastigial and contralateral dentate and posterior interposed nuclei of the $\mathrm{Cb}$ to intermediate and deep layers of the superior colliculus. These projections are proposed to underlie control of saccades [May, 2006] and visually guided head and neck movements [Uchido et al., 1983]. Projections from the $\mathrm{Cb}$ to mid and deep layers of the OT in larval and postmetamorphic bullfrogs are bilateral. These bilateral projections, compared to the primarily contralateral projections in mammals, may relate to the different visuomotor behaviors of these different animals. The bullfrog $\mathrm{Cb}$ is structurally less complex than the mammalian $\mathrm{Cb}$, and homologies between different regions are uncertain. The relative simplicity of the bullfrog $\mathrm{Cb}$ may be reflected in the lack of multiple indirect projections to the OT.

Hindbrain-tectal projections have been described in both larval and adult Xenopus [Lowe, 1987; Zittlau et al., 1988; Chahoud et al., 1996; Deeg et al., 2009; Hiramoto and Cline, 2009]. The reciprocal interconnections between the OT and the mesencephalic and medullary RG that we observed in bullfrog tadpoles are consistent with those previously reported in other species of adult anurans [Wilczynski and Northcutt, 1977; Lazar et al., 1983; Zittlau et al., 1988; Masino and Grobstein, 1990] and in some adult mammals [May, 2006]. Our data show the existence of strong bilateral connections between the OT and the MVN and LVN at all stages of development. Neither Wilczynski and Northcutt [1977] nor Masino and Grobstein [1990] identified any projections between the OT and the dorsal medulla in adult $R$. pipiens, even after very large HRP injections. Their data do show extensive fiber projections to the ventral medulla, and it is possible that the tracer they used simply did not travel far enough along the vap to reach the dap and the dorsal medulla. The bilateral projections we identify may represent more extensive transport of our tracers through the arcuate pathways to the opposite side of the medulla, or may reflect species and developmental differences.

Again consistent with the data from larval Xenopus [Chahoud et al., 1996; Hiramoto and Cline, 2009], we ob- 
served retrograde cell body label in the LLa in early and late larval bullfrog tadpoles. This label disappears during metamorphic climax, consistent with the degeneration of peripheral lateral line neuromasts in bullfrogs during this developmental time [Simmons and Horowitz, 2006]. Lateral line connectivity to the OT has been confirmed electrophysiologically in adult Xenopus [Lowe, 1987], but has not been confirmed in larval anurans of any species.

The trigeminal nucleus, which subserves proprioception of the head region, projects to the OT of larval and adult Xenopus [Zittlau et al., 1988; Chahoud et al., 1996; Deeg et al., 2009] and to the superior colliculus of some developing and adult mammals [McHaffie et al., 1986; May, 2006]. Trigeminal input to the OT was not observed in adult $R$. pipiens [Wilczynski and Northcutt, 1977; Masino and Grobstein, 1990]. In Xenopus, Chahoud et al. [1996] reported that the trigeminal projection is bilateral and arises during metamorphic climax stages, while Deeg et al. [2009] showed that trigeminal input to the OT is contralateral during early larval stages. We observed sparse bilateral cell body label in the trigeminal nucleus beginning in late larval stages and extending to adult stages.

Neurobiotin label of the dorsal arcuate pathway was moderate to heavy, and typically extended across the entire medial-lateral extent of this pathway, through the midline of the brain. Near the midline, we also observed some CT $\beta$ label of fiber segments and cell bodies in and around the abducens nucleus. It is possible that this cell label reflects leakage of tracer from dap fibers into collaterals of abducens cells. On the other hand, cell body and terminal label in and around the abducens nucleus following injections of dextran amine into the OT have been observed in adult goldfish [Pérez-Pérez et al., 2003]. The absence of direct tectal efferents to the abducens nucleus in our data is consistent with previous results in adult $R$. temporaria [Cochran et al., 1984].

Afferent input from the SON to the OT has not been described previously in adult anurans [Wilczynski and Northcutt, 1977; Masino and Grobstein, 1990; Zittlau et al., 1988]. We observed sparse retrograde cell body label in the ipsilateral SON and sparse to moderate fiber label around and passing through the SON, most commonly after injections into the lateral OT. HRP-labeled fibers and some terminals have been observed around the area of the SON in other species of adult ranids [Lazar et al., 1983, Masino and Grobstein, 1990]. We consistently observe more extensive label in the paragigantocellular nucleus adjacent to the SON than in the SON itself. These differences in label between these adjacent medullary ar- eas again suggest that tracer leakage cannot fully account for our results.

\section{Developmental and Species Differences in \\ Telencephalic Projections}

Damage to the telencephalon disrupts visual prey-orienting behaviors in adult Bufo bufo and R. pipiens [Ewert et al., 1983; Patton and Grobstein, 1998]. The caudal striatum seems most involved in producing these deficits, while damage to either the MP or the septum appears to have little effect [Patton and Grobstein, 1998]. Evidence for direct tectal-telencephalic connections in adult ranid frogs is inconclusive [Wilczynski and Northcutt, 1983; Masino and Grobstein, 1990; Northcutt and Ronan, 1992; Marín et al., 1997]. Some authors report no direct connections between the OT and the striatum [Wilczynski and Northcutt, 1983], while others [Masino and Grobstein, 1990; Marín et al., 1997] observed some cell label in the striatum after tracer injections into the OT. Our data show the presence of sparse retrograde cell label in the striatum after tracer injections into the OT in postmetamorphic bullfrogs, but not in tadpoles. We also observed neurobiotin-labeled fibers passing through the caudal ventral striatum, apparently progressing towards the septum, at all stages of development.

In adult Hyla versicolor, Endepols et al. [2005] observed neurobiotin-labeled fibers projecting from the septal nuclei via the mfb to the thalamus, with a disynaptic projection to the OT. Between late larval and froglet stages, we observed widespread cell and fiber label in both the MS and the LS after either neurobiotin or CT $\beta$ injections into the OT. Because label of the MS and LS was observed in the same larval brains where direct label of the striatum was absent, it is unlikely that the observed label in the MS and LS is due to leakage through the pretectum or thalamus. In adult bullfrogs, label in the MS is sparser and restricted to the region immediately adjacent to the periventricular zone. These data suggest that the direct tectal-septal connections present in tadpoles become pruned in adult bullfrogs, leading to patterns of connections more similar to that seen in $H$. versicolor.

Previous work using different tracers showed that the MP of adult bullfrogs [HRP: Northcutt and Ronan, 1992] and adult $R$. perezi [dextran amines: Marín et al., 1997] projects to the OT indirectly, through the septum and the pretectum. Our data show sparse retrograde cell label in the MP after OT injections, beginning in late larval tadpoles and extending into the adult period. A direct pallial-tectal pathway has also been reported in 1 species of adult shark and 1 species of adult ray [Smeets, 1982]. It 
has been proposed that the MP is a homolog of the mammalian hippocampus [Northcutt and Ronan, 1992]; this suggests that a pallial-tectal pathway might influence visual-spatial memory in frogs. The possibility that such a pathway may exist in tadpoles suggests that their spatial behavior may be more complex than currently realized.

\section{Tectal Control of Orienting Behaviors in}

\section{Developing Frogs}

Little systematic research has been conducted into tadpole visual behaviors. Optomotor nystagmus and horizontal eye movements in conjunction with oscillatory head movements during swimming have been observed in late larval stages [Stehouwer, 1987; younger animals were not tested in that experiment]. Ranid tadpoles do not exhibit vertical eye movements, as these are probably of limited usefulness during swimming and grazing. During metamorphic climax, eye blinks [Stehouwer, 1988] and nictitating membranes first appear, and binocular overlap increases as the eyes complete their dorsal migration. Adult bullfrogs rarely display spontaneous eye movements or saccades, and their compensatory eye movements are limited in range. They typically move their heads to maintain visual gaze, particularly in response to large displacements of the body [Dieringer and Precht, 1982]. Bullfrogs do not actively stalk prey but are ambush predators, remaining motionless until the prey item moves into their large visual fields [Stehouwer, 1987]. They then leap towards the prey, or strike it with their long extended tongues. Eyes are fully retracted into their orbits during swallowing as well as during ballistic leaps.

Both during swimming and quadrupedal locomotion, vestibulo-ocular reflexes are crucial for reorienting the body or the head on visual targets, while simultaneously maintaining balance either in the water column or on a substrate. The importance of these reflexes throughout life is consistent with the developmental stability of connectivity that we observed between the OT and nuclei in the medulla that receive vestibular input. In adult mammals, projections between the MVN and the superior colliculus, similar to what we observe, are important for coordination of the eyes and head [May, 2006]. In adult $R$. esculenta, the MVN and the LVN project to the $\mathrm{Cb}$, the oculomotor nuclei, and the spinal cord, completing a complex loop between vestibular, visual, and motor nuclei to regulate these vestibulo-ocular reflexes [Cochran et al., 1984]. Our data point to the involvement of the OT in this anatomical loop across the tadpole-frog transition. The emergence of connectivity between the OT and the extraocular (trochlear, oculomotor) nuclei may set the stage in tadpoles for the neural control of developing eye blinks and nictitating membrane responses, and may facilitate the eye retraction during swallowing that will emerge postmetamorphically. The more extensive bilateral cerebellotectal connectivity seen during metamorphic climax and froglet stages may reflect the more extensive visuomotor control that will be required during quadrupedal locomotion and catching of live prey compared to during grazing while swimming. Finally, tadpole visual behaviors may be influenced by arousal via tectal connectivity with the mesencephalic and medullary RG. In mammals, the paragigantocellular area is involved in the regulation of arousal through a wide array of autonomic circuits [Horowitz et al., 2004]. The connectivity we observe between the OT and the paragigantocellular area suggests that tadpole visual behaviors may similarly be influenced by autonomic events through this pathway.

\section{Acknowledgements}

This research was supported by National Institutes of Health Grant R01 DC05257 and by the RI Space Grant (NASA). We thank Victoria Flores, Daniel H. Miller, Paul Monfils, and Leslie H. Tanyu for assistance.

\section{References}

\begin{tabular}{|c|c|c|}
\hline $\begin{array}{l}\text { Boatright-Horowitz SS, Simmons AM (1995): } \\
\text { Postmetamorphic changes in auditory sensi- } \\
\text { tivity of the bullfrog midbrain. J Comp } \\
\text { Physiol A 177:577-590. } \\
\text { Boatright-Horowitz SS, Simmons AM (1997): } \\
\text { Transient 'deafness' accompanies auditory } \\
\text { development during metamorphosis from } \\
\text { tadpole to frog. Proc Natl Acad Sci USA 94: } \\
\text { 14877-14882. }\end{array}$ & $\begin{array}{l}\text { Chahoud BH, Cordier-Picouet MJ, Clairambault } \\
\text { P (1996): Larval development of tectal effer- } \\
\text { ents and afferents in Xenopus laevis (Am- } \\
\text { phibia Anura). J Brain Res 37:519-535. } \\
\text { Chen S, Aston-Jones G (1995): Evidence that } \\
\text { cholera toxin B subunit (CT } 3 \text { ) can be avidly } \\
\text { taken up and transported by fibers of pas- } \\
\text { sage. Brain Res 674:107-111. } \\
\text { Cliffer KD, Giesler GJ Jr (1988): PHA-L can be } \\
\text { transported anterogradely through fibers of } \\
\text { passage. Brain Res 458:185-191. }\end{array}$ & $\begin{array}{l}\text { Cochran SL, Dieringer N, Precht W (1984): Basic } \\
\text { optokinetic-ocular reflex pathways in the } \\
\text { frog. J Neurosci 4:43-57. } \\
\text { Dann JF, Beazley LD (1982): The development of } \\
\text { connections between the isthmic nucleus } \\
\text { and the tectum in Xenopus and Limnodynas- } \\
\text { tes tadpoles. Neurosci Lett 33:107-113. } \\
\text { Dann JF, Beazley LD (1990): Development of top- } \\
\text { ographic connections between the isthmic } \\
\text { nuclei and optic tecta in the frog, Limnodyn- } \\
\text { astes dorsalis. Anat Embryol 181:167-176. }\end{array}$ \\
\hline
\end{tabular}


Debski EA, Constantine-Paton M (1993): The development of non-retinal afferent projections to the frog optic tectum and the substance P immunoreactivity of tectal connections. Develop Brain Res 72:21-39.

Deeg KE, Sears IB, Aizenman CD (2009): Development of multisensory convergence in Xenopus optic tectum. J Neurophysiol 102:33923404.

- Dieringer N, Precht W (1982): Compensatory head and eye movements in the frog and their contribution to stabilization of gaze. Exp Brain Res 47:394-406.

Endepols H, Roden K, Walkowiak W (2005): Hodological characterization of the septum in anuran amphibians. II. Efferent connections. J Comp Neurol 483:437-457.

Ewert J-P, Burghagen $\mathrm{H}$, Schurg-Pfeiffer E (1983): Neuroethological analysis of innate releasing mechanism for prey-catching behavior in toads; in Ewert J-P, Capranica RR, Ingle D (eds): Advances in Vertebrate Neuroethology. New York, Plenum, pp 413-476.

-Gerfen CR, Sawchenko PE (1984): An anterograde neuroanatomical tracing method that shows the detailed morphology of neurons, their axons and terminals: immunohistochemical localization of an axonally transported plant lectin, Phaseolus vulgaris leucoagglutinin (PHA-L). Brain Res 290:219238.

Gosner KL (1960): A simplified table for staging anuran embryos and larvae with notes on identification. Herpetologica 16:183-190.

-Grobstein P, Comer C (1983): The nucleus isthmi as an intertectal relay for the ipsilateral oculotectal projection in the frog, Rana pipiens. J Comp Neurol 217:54-74.

-Grobstein P, Comer C (1977): Postmetamorphic eye migration in Rana and Xenopus. Nature 269:54-56.

Hiramoto M, Cline HT (2009): Convergence of multisensory inputs in Xenopus tadpole tectum. Develop Neurobiol 69:959-971.

- Hofmann MH, Ebbesson SOE, Meyer DL (1990): Tectal afferents in Rana pipiens. A reassessment questioning the comparability of HRP results. J Hirnforsch 31:337-340.

Horowitz SS, Simmons AM (2007): Dynamic visualization of the developing nervous system of the bullfrog, Rana catesbeiana. Brain Res 1157:23-31.

Horowitz SS, Blanchard J, Morin LP (2004): Medial vestibular connections with the hypocretin (orexin) system. J Comp Neurol 487: 127-146.

-Horowitz SS, Tanyu LH, Simmons AM (2007a): Multiple mechanosensory modalities influence development of auditory function. J Neurosci 27:782-790.

-Horowitz SS, Chapman JA, Simmons AM (2007b): Plasticity of auditory medullarymidbrain connectivity across metamorphic development. Brain Behav Evol 69:1-19.

Huang Q, Zhou D, DiFiglia M (1992): Neurobiotin, a useful neuroanatomical tracer for in vivo anterograde, retrograde and transneu- ronal tract-tracing and for in vitro labeling of neurons. J Neurosci Methods 41:31-43.

Ikenaga T, Yoshida M, Uematsu K (2002): Efferent connections of the cerebellum in the goldfish Carassius auratus. Brain Behav Evol 60:36-51.

Jacquin MF, Hu JW, Sessle BJ, Renehan WE, Waite PM (1992): Intra-axonal Neurobiotin injection rapidly stains the long-range projections of identified trigeminal primary afferents in vivo: comparisons with HRP and PHA-L. J Neurosci Methods 45:71-86.

Jacobson M (1971): Absence of adaptive modification in developing retinotectal connections in frogs after visual deprivation or disparate stimulation of the eyes. Proc Nat Acad Sci USA 68:528-532.

Kennard C, Keating MJ (1985): A species difference between Rana and Xenopus in the occurrence of intertectal neuronal plasticity. Neurosci Lett 58:5365-5370.

Lazar G, Toth P, Csank G, Kicliter E (1983): Morphology and location of tectal projection neurons in frogs: a study with HRP and cobalt-filling. J Comp Neurol 215:108-120.

Lowe DA (1987) Single-unit study of lateral line cells in the optic tectum of Xenopus laevis: evidence for bimodal lateral line/optic units. J Comp Neurol 257:396-404.

Luppi PH, Aston-Jones G, Akaoka H, Chouvet G, Jouvet M (1995): Afferent projections to the rat locus coeruleus demonstrated by retrograde and anterograde tracing with cholera-toxin B subunit and Phaseolus vulgaris leucoagglutinin. Neuroscience 65 119-160.

Marín O, González A, Smeets WJAJ (1997): Anatomical substrate of amphibian basal ganglia involvement in visuomotor behavior. Eur J Neurosci 9:2100-2109.

-Masino T, Grobstein P (1990): Tectal connectivity in the frog Rana pipiens: tectotegmental projections and a general analysis of topographic organization. J Comp Neurol 291: 103-27.

May PJ (2006): The mammalian superior colliculus: laminar structure and connections. Prog Brain Res 151:321-378.

McHaffie JG, Ogasawara K, Stein BE (1986): Trigeminotectal and other trigeminofugal projections in neonatal kittens: an anatomical demonstration with horseradish peroxidase and tritiated leucine. J Comp Neurol 249: 411-427.

Montgomery N, Fite KV (1991): Organization of ascending projections from the optic tectum and mesencephalic pretectal gray in Rana pipiens. Vis Neurosci 7:459-478.

Nieuwenhuys R, Opdam R (1976): Structure of the brain stem; in Llinás R, Precht W (eds): Frog Neurobiology. New York, Springer, pp 811-855.

Northcutt RG, Ronan M (1992): Afferent and efferent connections of the bullfrog medial pallium. Brain Behav Evol 40:1-16.

Patton P, Grobstein P (1998): The effects of telencephalic lesions on visually mediated prey orienting behavior in the leopard frog (Rana pipiens). Brain Behav Evol 51:144-161.

Pérez-Pérez MP, Luque MA, Herrero L, NunezAbades PA, Torres B (2003): Connectivity of the goldfish optic tectum with the mesencephalic and rhombencephalic reticular formation. Exp Brain Res 151:123-135.

Reh TA, Constantine-Paton M (1984): Retinal ganglion cell terminals change their projection sites during larval development of Rana pipiens. J Neurosci 4:442-457.

-Sakaguchi DS, Murphey RK (1985): Map formation in the developing Xenopus retinotectal system: an examination of ganglion cell terminal arborizations. J Neurosci 5:32283245.

Simmons AM, Horowitz SS (2006): Plasticity in the auditory system across metamorphosis, in: Narins PM, Feng AS, Popper AN, Fay RR (eds): Hearing and Sound Communication in Amphibians. New York, Springer, pp 291322.

Smeets WJAJ (1982): The afferent connections of the tectum mesencephali in two chondrichthyans, the shark Scyliorhinus canicula and the ray Raja clavata. J Comp Neurol 205: 139-152.

Stehouwer DJ (1987): Effect of tectotomy and decerebration on spontaneous and elicited behavior of tadpoles and juvenile frogs. Behav Neurosci 101:378-384.

-Stehouwer DJ (1988): Metamorphosis of behavior in the bullfrog (Rana catesbeiana). Dev Psychobiol 21:383-395.

-Udin SB, Fisher MD (1985): The development of the nucleus isthmi in Xenopus laevis. I. Cell genesis and the formation of connections with the tectum. J Comp Neurol 232: 25-35.

- Uchido K, Mizuno N, Sugimoto T, Itoh K, Kudo M (1983): Direct projections from the cerebellar nuclei to the superior colliculus in the rabbit: An HRP study. J Comp Neurol 216: 319-326.

Uray NJ, Gona AG (1999): Calbindin immunoreactivity in the auricular lobe and interauricular granular band of the cerebellum in bullfrogs. Brain Behav Evol 53:10-19.

Wada M, Urano A, Gorbman A (1980): A stereotaxic atlas for diencephalic nuclei of the frog, Rana pipiens. Arch Histol Jap 43:157-173.

Wassersug RJ (1971): Aspects of social behavior in anuran larvae; in Vail JL (ed): Evolutionary Biology of the Anurans: Contemporary Research on Major Problems. Columbia, University of Missouri Press, pp 273-297.

-Wilczynski W, Northcutt RG (1977): Afferents to the optic tectum of the leopard frog: an HRP study. J Comp Neurol 173:219-230.

-Wilczynski W, Northcutt RG (1983): Connections of the bullfrog striatum: afferent organization. J Comp Neurol 214:321-332.

Zittlau KE, Claas B, Munz H (1988): Horseradish peroxidase study of tectal afferents in Xenopus laevis with special emphasis on their relationship to the lateral-line system. Brain Behav Evol 32:208-219. 